\title{
Paraoxonase (PON1 and PON3) polymorphisms: impact on liver expression and atorvastatin-lactone hydrolysis
}

\author{
Stephan Riedmaier ${ }^{1}$, Kathrin Klein ${ }^{1}$, Stefan Winter ${ }^{1}$, Ute Hofmann ${ }^{1}$, Matthias Schwab ${ }^{1,2}$ and \\ Ulrich M. Zanger ${ }^{1}$ \\ 1 Dr. Margarete Fischer-Bosch Institute of Clinical Pharmacology, University of Tuebingen, Stuttgart, Germany \\ ${ }^{2}$ Department of Clinical Pharmacology, Institute of Experimental and Clinical Pharmacology and Toxicology, University Hospital Tuebingen, Tuebingen, Germany
}

\author{
Edited by: \\ Ann K. Daly, University of Newcastle \\ upon Tyne, UK \\ Reviewed by: \\ Norio Yasui-Furukori, Hirosaki \\ University, Japan \\ Jean-Marie Dupret, University Paris \\ Diderot, France \\ *Correspondence: \\ Ulrich M. Zanger, Dr. Margarete \\ Fischer-Bosch Institute of Clinical \\ Pharmacology, Auerbachstr 112, \\ D-70376 Stuttgart, Germany. \\ e-mail: uli.zanger@ikp-stuttgart.de
}

Atorvastatin $\delta$-lactone, a major, pharmacologically inactive metabolite, has been associated with toxicity. In a previous study we showed that polymorphisms of UGT1A3 influence atorvastatin $\delta$-lactone formation. Here we investigated the reverse reaction, atorvastatin $\delta$-lactone hydrolysis, in a human liver bank. Screening of microarray data revealed paraoxonases PON1 and PON3 among 17 candidate esterases. Microsomal $\delta$-lactone hydrolysis was significantly correlated to PON1 and PON3 protein $\left(r_{\mathrm{s}}=0.60 ; r_{\mathrm{S}}=0.62\right.$, respectively; $P<0.0001)$. PON1 and PON3 were strongly correlated to each other $\left(r_{s}=0.60\right)$ but PON1 was shown to be more extensively glycosylated than PON3. In addition a novel splicevariant of PON3 was identified. Genotyping of 40 polymorphisms within the PON-locus identified PON1 promoter polymorphisms $(-108 \mathrm{~T}>\mathrm{C},-832 \mathrm{G}>\mathrm{A},-1741 \mathrm{G}>\mathrm{A})$ and a tightly linked group of PON3 polymorphisms $(-4984 A>G,-4105 G>A,-1091 A>G$, $-746 C>T$, and $\mathrm{F} 21 \mathrm{~F}$ ) to be associated with changes in atorvastatin $\delta$-lactone hydrolysis and expression of PON1 but not PON3. However, carriers of the common PON1 polymorphisms L55M or Q192R showed no difference in $\delta$-lactone hydrolysis or PON expression. Haplotype analysis revealed decreased $\delta$-lactone hydrolysis in carriers of the most common haplotype ${ }^{*} 1$ compared to carriers of haplotypes ${ }^{*} 2,{ }^{*} 3,{ }^{*} 4$, and ${ }^{*} 7$. Analysis of non-genetic factors showed association of hepatocellular and cholangiocellular carcinoma with decreased PON1 and PON3 expression, respectively. Increased C-reactive protein and $\gamma$-glutamyl transferase levels were associated with decreased protein expression of both enzymes, and increased bilirubin levels, cholestasis, and presurgical exposure to omeprazole or pantoprazole were related to decreased PON3 protein. In conclusion, PON-locus polymorphisms affect PON1 expression whereas non-genetic factors have an effect on PON1 and PON3 expression. This may influence response to therapy or adverse events in statin treatment.

Keywords: atorvastatin-lactone, myopathy, rhabdomyolysis, paraoxonase, PON1, PON3, SNP, pharmacogenetics

\section{INTRODUCTION}

Statins are generally well tolerated drugs. Severe adverse events are rare, but hepatotoxicity, myopathy, and rhabdomyolysis are well known. One to $5 \%$ of patients develop muscle pain symptoms often leading to discontinuation of treatment (Thompson et al., 2003). A comprehensive explanation for the development of the described adverse events has not yet been found. One plausible mechanism proposes inhibition of an early step of the cholesterol biosynthesis, reducing not only cholesterol as intended, but also production of mevalonate pathway products like ubiquinone (Coenzyme Q10) or isoprenoids/terpenoids (Baer and Wortmann, 2007; Marcoff and Thompson, 2007). On the other hand it was shown that highly metabolized statins like atorvastatin were associated with the highest risk for adverse events (Law and Rudnicka, 2006; Silva et al., 2006). This is further emphasized by reports of increased numbers of adverse events when statins are co-administered with known inhibitors of statin metabolizing enzymes. A striking example is the fibrate gemfibrozil where combinations with cerivastatin have greatly increased the rate of rhabdomyolysis (Neuvonen et al., 2006) due to the inhibitory effect of gemfibrozil and its glucuronide metabolite on CYP2C8 and OATP1B1 dependent metabolism and transport, respectively (Shitara and Sugiyama, 2006). After the death of several people caused by this co-medication, it was decided to withdraw cerivastatin from the market.

Recent observations highlight the role of certain metabolites for adverse events or response to atorvastatin. Hermann et al. (2006) compared the pharmacokinetics of atorvastatin and its metabolites in healthy controls and myopathy patients. Interestingly, myopathy patients had 2.4- and 3.1-fold increased AUC values for atorvastatin-lactone and para-hydroxy-atorvastatin, respectively. Moreover, by assessing the myotoxic potency of atorvastatin and metabolites in primary skeletal muscle cells, it was found that atorvastatin-lactone had a 14-fold higher potency to induce cell-death compared to atorvastatin-acid (Skottheim et al., 2008). These facts point to an involvement of certain metabolites in 
the development of statin-associated adverse events. Furthermore, atorvastatin is administered as active acid form but like other statins it is also found with nearly equal AUC in its inactive lactone form (Kantola et al., 1998). Both, the acid and the lactone form are substrates of CYP3A4 and CYP3A5, which convert them to the respective para- $(\mathrm{pOH})$ and ortho- $(\mathrm{oOH})$ hydroxy-metabolites. However, due to their higher lipophilicity the lactones are much better substrates with identical $(\mathrm{oOH})$ or even six-fold higher (pOH) $V_{\max }$ and about 20-fold lower $K_{\mathrm{m}}$, due to better access to the hydrophobic substrate channel of the CYP enzyme near the membrane surface (Jacobsen et al., 2000). It has therefore been suggested that elimination of atorvastatin may proceed primarily via hydroxylation of atorvastatin-lactone and not via hydroxylation of the parent compound (Jacobsen et al., 2000).

We therefore hypothesized that enzymatic conversion between atorvastatin-acid and atorvastatin-lactone and vice versa may constitute an additional level of variation that could in principle be affected by both genetic and non-genetic factors. Conversion of atorvastatin to the lactone has been reported to occur spontaneously at low intestinal pH (Kearney et al., 1993) but proceeds predominantly enzymatically at physiological $\mathrm{pH}$ (Goosen et al., 2007). Enzymatic formation was shown to occur via acyl-glucuronidation followed by spontaneous conversion to the lactone (Prueksaritanont et al., 2002). Recently we could show that UDP-glucuronosyltransferase UGT1A3 is the main enzyme responsible for the lactonization of atorvastatin. As a result, UGT1A-polymorphisms affecting UGT1A3 expression were found to significantly increase atorvastatin-lactone formation (Riedmaier et al., 2010).

The reverse reaction, hydrolysis of the lactone to the open acid conformation may happen chemically or enzymatically via esterases or paraoxonases (Testa and Mayer, 2003). Such a conversion by paraoxonase 1 (PON1) has been shown for simvastatin and lovastatin (Billecke et al., 2000) and by paraoxonase 3 (PON3) for lovastatin (Draganov et al., 2005). Hydrolysis of atorvastatinlactone by these enzymes has not been examined before to the best of our knowledge. The three members of the paraoxonase family, PON1, PON2, and PON3, are primarily lactone hydrolyzing enzymes and share an amino acid identity of $\sim 65 \%$. The PON1 structure consists of a six-bladed beta-propeller containing two $\mathrm{Ca}^{2+}$ ions necessary for enzyme stability and activity (Draganov, 2010). The activity of PON3 was also found to be $\mathrm{Ca}^{2+}$ dependent (Lu et al., 2006). Polymorphisms of PON1 have been studied extensively in the context of its antioxidative potential in coronary artery disease and stroke (Ranade et al., 2005; Banerjee, 2010; Dahabreh et al., 2010) and most recently an involvement in the generation of the active metabolite of clopidogrel has been proposed (Bouman et al., 2011). Several of the studied polymorphisms indeed affect PON1 expression or activity. A functional promoter polymorphism $(-108 T>C$; rs705379) with variant allele frequency (VAF) of $38.9 \%$ in Caucasians was reported to disrupt the binding site for transcription factor Sp1 (Deakin et al., 2003) or AhR (Gouédard et al., 2004). Two coding polymorphisms (Q192R; rs662; VAF $=35.8 \%$ in Caucasians; L55M; rs854560; VAF $=39.7 \%$ in Caucasians) were shown to change the catalytic activity for several substrates (Costa and Furlong, 2002). Much less is known about the variability of PON3 and potential polymorphic markers for expression and function. Although several promoter polymorphisms were studied in relation to PON1 substrates their functional relevance remained unclear (Marsillach et al., 2009).

In this study, we hypothesized that paraoxonases may play an active role in the hydrolysis of atorvastatin-lactone, and that interpatient variation in the expression and activity of these enzymes could be a determinant of atorvastatin response and/or toxicity. We investigated this hypothesis in vitro in a large human liver bank. By determining the population variability and using correlation analysis we provide evidence that both PON1 and PON3 contribute to atorvastatin-lactone hydrolysis. Further, we investigated the influence of 40 genetic polymorphisms at the PON-locus as well as of several non-genetic factors on expression and function of these genes. We identified several polymorphisms and haplotypes that are associated with changes in atorvastatin $\delta$-lactone hydrolysis and PON expression. Hence, this comprehensive analysis renders the $P O N$-locus a promising candidate that could influence patients' response to atorvastatin treatment.

\section{RESULTS}

\section{GENERAL ROLE OF ENZYMATIC LACTONE HYDROLYSIS}

First experiments based on published results for lovastatin hydrolysis indicated that in human liver microsomes both spontaneous and enzymatic conversion of lovastatin-lactone and atorvastatinlactone to the acid forms occurs. Enzymatic compared to spontaneous hydrolysis, the latter of which was assessed by identical incubation with heat-inactivated protein fractions, was found to be 1.3-fold higher for lovastatin-lactone and 3.8-fold higher for atorvastatin-lactone in a pooled microsomal fraction (data not shown). In all subsequent analyses with atorvastatin-lactone, control incubations with heat-inactivated protein $\left(95^{\circ} \mathrm{C}, 5 \mathrm{~min}\right)$ were included and the respective background was subtracted.

\section{VARIABILITY OF MICROSOMAL ATORVASTATIN-LACTONE HYDROLYSIS}

Next we determined enzymatic atorvastatin-lactone hydrolysis in a large number of microsome samples $(N=142)$. Establishing the atorvastatin-lactone hydrolysis assay, we could show that the activity was increased by approximately $20 \%$ by adding $1 \mathrm{mM} \mathrm{CaCl}_{2}$, although these reactions are not depending on co-substrates. Figure 1 shows the variability of atorvastatin-lactone hydrolysis in our cohort of human liver samples. The fraction of enzymatic lactone hydrolysis ranged from 0 to $42 \%$ of total atorvastatinacid formation indicating a large interindividual variability of the enzymatic fraction of the reaction. Comparison of the coefficients of variation revealed similar variability for UGT1A3-dependant lactone formation (Riedmaier et al., 2010) and enzymatic lactone hydrolysis (62 and 54\%, respectively). Of note, UGT enzymes are only active in the presence of UDP-glucuronic acid. This cofactor was not included in the atorvastatin-lactone hydrolyzing assay.

\section{CANDIDATE ESTERASE SCREENING}

Our next aim was to identify the enzyme(s) responsible for this conversion. Since several enzymes known to possess esterase activity were possibly involved (Testa and Mayer, 2003), we used mRNA profiling data previously obtained by microarray analysis of the liver samples (Schröder et al., manuscript submitted). 
Table 1 shows the results of a correlation analysis between mRNA expression data of a selection of candidate esterases and enzymatic atorvastatin-lactone hydrolysis activity in the human livers. The analysis included acetylcholinesterase (ACHE), acyl-CoA thioesterase 1 (ACOT1), albumin (ALB), butyrylcholinesterase (BCHE), carboxyl ester lipase (CEL), carboxylesterase (CES1, 2, 3, 4, 7), paraoxonases (PON1, 2, 3), lysosomal acid, cholesterol esterase (LIPA), and sialic acid acetylesterase (SIAE). Interestingly, this analysis identified PON1 and PON3, already known to be involved in the hydrolysis of simvastatin and lovastatin (Draganov et al., 2005; Suchocka et al., 2006) as the two top candidates. Significant correlations (Holm-adjusted $P<0.05$ ) were also observed for BCHE, CES3 (positive) and PON2, LIPA (negative).

\section{POPULATION VARIABILITY OF MICROSOMAL PON1 AND PON3 EXPRESSION}

In further experiments we concentrated on PON1 and PON3, because their expression showed the strongest correlation to atorvastatin-lactone hydrolysis. To quantitate mRNA transcripts by real-time PCR, we first carried out RT-PCR experiments to quantitate distinct transcripts described for PON1 (four splice-variants; Ensembl: ENSG00000105852) and PON3 (nine splice-variants; Ensembl: ENSG00000005421). We identified the

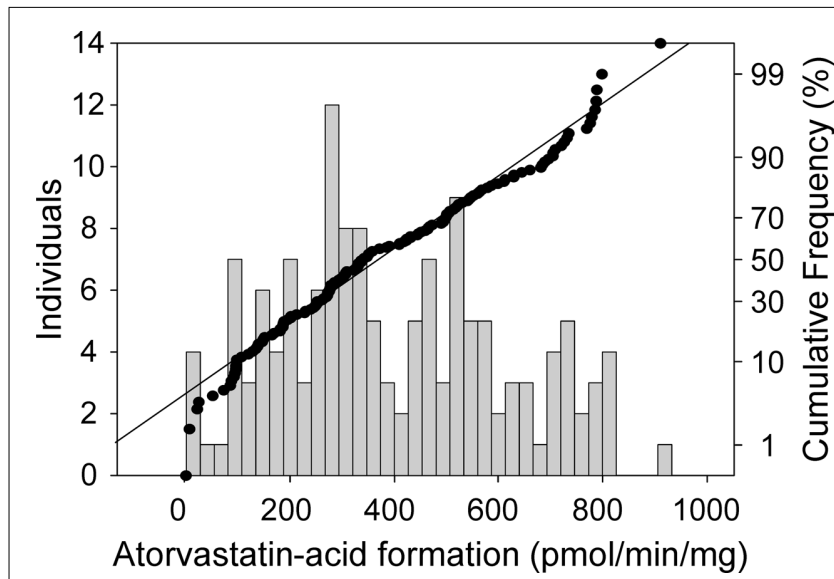

FIGURE 1 | Frequency histogram (left axis) and cumulative frequency (right axis) showing population distribution of the hydrolysis of atorvastatin-lactone $(10 \mu \mathrm{M})$ to atorvastatin-acid in human liver microsomes ( $N=\mathbf{1 4 2}$ ). Incubations (5 $\mu \mathrm{g}$ of microsomal protein) were performed in the presence of $1 \mathrm{mM} \mathrm{CaCl}$ at $37^{\circ} \mathrm{C}$ for $30 \mathrm{~min}$.

Atorvastatin-acid was quantitated by LC-MS/MS analysis. predicted PON1 and PON3 wild type transcripts and a novel variant PON3 mRNA species, which was shown by sequence analysis to contain an additional exon of $144 \mathrm{bp}$ (corresponding to 48 amino acids) between exons 3 and 4 . No other PON3 variants were detected using primers for full-length mRNA amplification in a subset of 20 samples. On average, this splice-variant was 3.1-fold less expressed compared to wild type. When comparing the coefficients of variation, mRNA levels of PON3 wild type and variant were similarly variable ( 40 and $43 \%$, respectively). Quantification of mRNA expression of PON1 and PON3 by self-designed specific TaqMan assays revealed that PON3 wild type mRNA was on average 5.1-fold higher expressed than PON1 mRNA (for correlations see below). PON1 mRNA had a high coefficient of variation (150\%).

Protein expression of PON1 and PON3 was quantified by Western blot analysis using monoclonal primary antibodies. PON1 was identified as a triple band in a range of approximately $35-40 \mathrm{kDa}$, in agreement with earlier data on purified human serum paraoxonase (Furlong et al., 1991; Gan et al., 1991; Figure 2A). These bands occurred only in human liver microsomes but not in cytosol. PON3, on the other hand, was found as a single band at $38 \mathrm{kDa}$ in human liver microsomes. In cytosolic samples of the same livers as well as in a sample prepared from primary human hepatocytes, two bands at 21 and $35 \mathrm{kDa}$ were identified, whereas the $38-\mathrm{kDa}$ band was absent (Figure 2B). The PON3 variant was not detected. Endoglycosidase treatment was performed to test whether glycosylation was responsible for the various immunoreactive proteins. Treatment of human liver microsomes lead to a shift of the detected bands toward a single $35 \mathrm{kDa}$ band with both antibodies (Figure 2C). This finding suggested that PON1 and PON3 are highly glycosylated proteins in microsomes. Remarkably, the $35 \mathrm{kDa}$ band, presumably representing the unglycosylated PON1 and PON3 forms corresponded to one of the two PON3 bands detected in human liver cytosol and in hepatocytes. The observed microsomal pattern of three bands for PON1 and one band for PON3 corresponded to three reported glycosylation sites (amino acids N226, N252, and N323) on PON1 and one site (N323) on PON3 (Liu et al., 2005). For quantification, the liver samples were analyzed in their glycosylated state and the relevant signals were combined.

Taken together, these analyses revealed that both PON1 and PON3 varied considerably with regard to the analyzed phenotypes of expression and atorvastatin-lactone hydrolysis. Table 2 presents an overview of the PON population variability parameters at mRNA and protein/function levels. All measured phenotypes were not normally distributed in our Caucasian liver donor cohort. The

Table 1 | Correlation analysis of candidate gene expression and atorvastatin-lactone hydrolysis.

\begin{tabular}{|c|c|c|c|c|c|c|c|c|}
\hline & ACHE & ACOT1 & ALB & BCHE & CEL & CES1 & CES2 & CES3 \\
\hline \multirow[t]{2}{*}{ Atorvastatin-acid formation } & $r_{\mathrm{s}}=0.21^{*}$ & n.s. & n.s. & $r_{\mathrm{s}}=0.38^{* * *}$ & n.s. & $r_{\mathrm{s}}=0.24^{*}$ & n.s. & $r_{\mathrm{s}}=0.35^{* * *}$ \\
\hline & CES4 & CES7 & PON1 & PON2 & PON3 & LIPA & SIAE & \\
\hline Atorvastatin-acid formation & n.s. & n.s. & $r_{\mathrm{s}}=0.40 * * *$ & $r_{\mathrm{s}}=-0.39 * * *$ & $r_{\mathrm{s}}=0.52 * * *$ & $r_{\mathrm{s}}=-0.32^{* * *}$ & $r_{\mathrm{s}}=-0.27^{* *}$ & \\
\hline
\end{tabular}

${ }^{*} p<0.05,{ }^{*} p<0.01,{ }^{* * *} p<0.001$. 

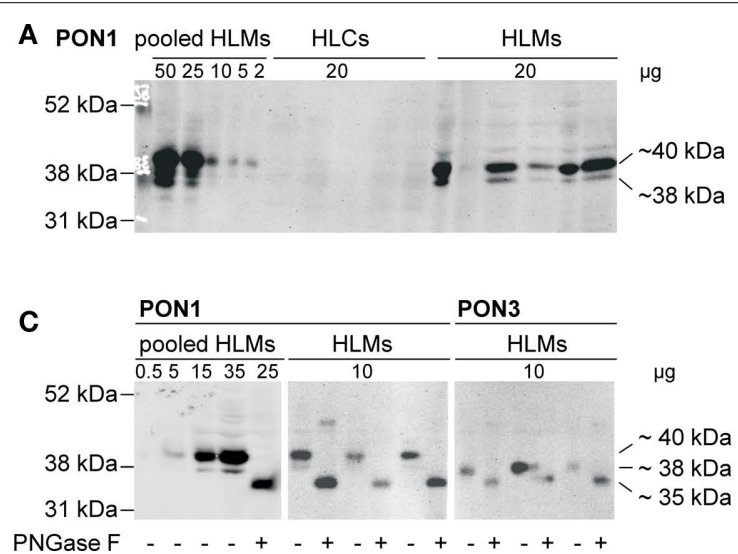

FIGURE 2 | Immunoblots of human liver cytosol (HLCs) and microsomes (HLMs) of livers 1-5 stained with specific antibodies against (A) PON1 and (B) PON3 (performed on identical blot after stripping). Analysis was performed on cytosolic and microsomal

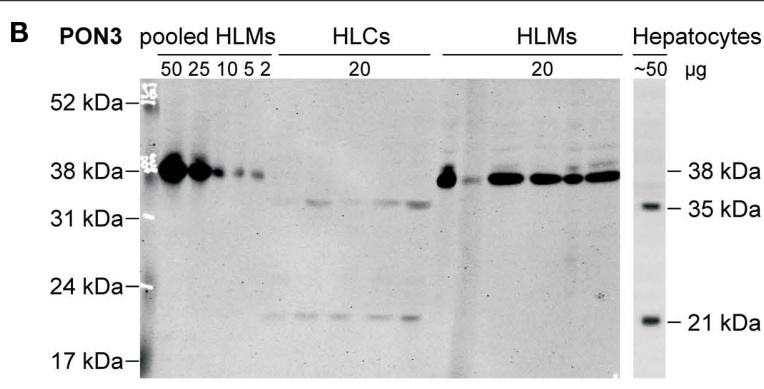

fractions of livers 1-5, on a human liver microsome pool (lane 11) and on lysate of primary human hepatocytes. (C) Deglycosylation was performed by analysis with $(+)$ or without $(-)$ pretreatment by endoglycosidase PNGase F.

Table 2 | Population variability of hepatic PON1 and PON3 expression phenotypes.

\begin{tabular}{|c|c|c|c|c|c|c|}
\hline & \multicolumn{2}{|c|}{ PON1 } & \multicolumn{3}{|c|}{ PON3 } & \multirow[b]{2}{*}{$\begin{array}{l}\text { Atorvastatin- } \\
\text { acid formation } \\
\text { (pmol/min } / \mathrm{mg} \text { ) }\end{array}$} \\
\hline & $\begin{array}{l}\text { mRNA/RPLPO } \\
\text { relative units }\end{array}$ & $\begin{array}{l}\text { Protein } \\
\text { (relative units) }\end{array}$ & $\begin{array}{l}\text { Wildtype } \\
\text { mRNA/RPLPO } \\
\text { relative units }\end{array}$ & $\begin{array}{l}\text { Variant } \\
\text { mRNA/RPLPO } \\
\text { relative units }\end{array}$ & $\begin{array}{l}\text { Protein } \\
\text { (relative units) }\end{array}$ & \\
\hline Minimum & 0.61 & 51.40 & 7.29 & 2.20 & 0.90 & 6.67 \\
\hline Median & 5.84 & 620.0 & 28.73 & 9.50 & 14.10 & 309.70 \\
\hline Maximum & 120.30 & 2200 & 73.74 & 22.51 & 74.65 & 816.0 \\
\hline Ratio max./min. & 196.25 & 42.80 & 10.12 & 10.23 & 82.94 & 122.34 \\
\hline Normal distribution & No & No & No & No & No & No \\
\hline Sample skewness & 6.88 & 1.05 & 0.67 & 0.58 & 1.44 & 0.30 \\
\hline Coefficient of variation (\%) & 150 & 69 & 40 & 43 & 74 & 54 \\
\hline
\end{tabular}

coefficient of variation was lowest for PON3 mRNA and activity, higher for PON1 and PON3 protein expression and highest for PON1 mRNA expression.

\section{IDENTIFICATION OF RESPONSIBLE HYDROLYZING ENZYMES BY CORRELATION ANALYSIS}

To further substantiate the involvement of PON1 and PON3 in atorvastatin-lactone hydrolysis, correlation analysis was performed. As shown in Table 3, rather strong associations above $r_{\mathrm{s}}>0.5$ (i.e., $r_{s}^{2}>0.25$; highlighted cells) were obtained for three parameter-pairs. Most notably, atorvastatin-lactone hydrolysis was correlated with similarly high Spearman coefficients to both, PON1 and PON3 protein expression, indicating that both enzymes contribute approximately equally to the microsomal enzymatic reaction. Furthermore the mRNAs of PON1 and PON3 (wildtype and splice-variant) were also significantly correlated to activity, although with lower Spearman coefficients. Moreover, correlations were also observed between transcripts, as well as between PON1 and PON3 protein indicating co-regulation of these two paraoxonases.

\section{GENETIC VARIABILITY AT THE PON-LOCUS}

We analyzed the genetic variability at the PON-locus to select known functional SNPs that cover the coding and regulatory regions of the two candidate genes PON1 and PON3. In addition, we included tagging SNPs selected for the less well characterized PON3 gene. In total we genotyped 7 promoter SNPs, 11 coding SNPs, 14 intronic SNPs, and $13^{\prime}$ UTR polymorphism of PON3 including the selected tagging SNPs. Furthermore three promoter SNPs, two amino acid changing polymorphisms of PON1, and two intergenic polymorphisms located between the two genes were included. A summary of the selected polymorphisms including a comparison of the measured VAF with published data is shown in Table A1 in Appendix. Major frequency deviations were observed for some polymorphisms derived from the Seattle SNP database, probably because only 23 subjects had been included in their analyses. For SNP 19, only data from a Chinese cohort was available and this polymorphism was much more common in our Caucasian population.

Calculation of pairwise LD values at the PON-locus revealed a block of tightly linked polymorphisms comprising the PON3 promoter region, several intronic polymorphisms and the 
synonymous polymorphisms F21F (rs13226149), and A99A (rs1053275; $D^{\prime}=0.88-1.0 ; r^{2}=0.04-1.0$; Figure 3$)$. Of note, this block is also linked to the $-1741 G>A$ PON1 promoter polymorphism $\left(D^{\prime}=0.49-1.0 ; r^{2}=0.09-0.43\right)$. Linkage was also detected between PON1 promoter polymorphisms and L55M ( $D^{\prime}=0.59$ $\left.0.87 ; r^{2}=0.14-0.19\right)$. PON1 Q192R on the other hand was only linked to $\mathrm{L} 55 \mathrm{M}\left(D^{\prime}=0.95 ; r^{2}=0.23\right)$, but neither to PON1 promoter polymorphisms nor to polymorphisms of the PON3 linkage block. Linkage was additionally detected between the rare polymorphisms $P O N 3-794 C>T, 3^{\prime} U T R$ rs17885558 and the intergenic polymorphism $\operatorname{rs} 7778771\left(\mathrm{VAF}=1.3 \% ; D^{\prime}=1\right.$; $\left.r^{2}=1\right)$.

\section{Association of PON polymorphisms with PON-related phenotypes}

Univariate analysis was carried out for association between single SNP genotypes and the PON phenotypes, atorvastatinlactone hydrolysis, PON1 and PON3 protein expression (Figures 4-6).

Table 3 | Correlation analyses of PON1 and PON3 expression and microsomal atorvastatin-lactone hydrolysis.

\begin{tabular}{llllll}
\hline PON1 protein & $\begin{array}{l}\text { PON3 WT mRNA } \\
\text { (exon 3-4) }\end{array}$ & $\begin{array}{l}\text { PON3 VAR mRNA } \\
\text { (exon 3a-4) }\end{array}$ & PON3 protein & $\begin{array}{l}\text { Atorvastatin-acid } \\
\text { formation }\end{array}$ \\
\hline$r_{\mathrm{s}}=0.45^{* * *}$ & $r_{\mathrm{s}}=0.42^{* * *}$ & $r_{\mathrm{s}}=0.40^{* * *}$ & $\mathrm{n}^{*} \mathrm{~s}$. & $r_{\mathrm{s}}=0.28^{* * *}$ & PON1 mRNA (exon 8-9) \\
& $r_{\mathrm{s}}=0.27^{* *}$ & $r_{\mathrm{s}}=0.28^{* * *}$ & $r_{\mathrm{s}}=0.48^{* * *}$ & $r_{\mathrm{s}}=0.60^{* * *}$ & PON1 protein \\
& & $r_{\mathrm{s}}=0.90^{* *}$ & $r_{\mathrm{s}}=0.31^{* * *}$ & $r_{\mathrm{s}}=0.33^{* *}$ & PON3 WT mRNA (exon 3-4) \\
& & & $r_{\mathrm{s}}=0.32^{* * *}$ & $r_{\mathrm{s}}=0.32^{* * *}$ & PON3 VAR mRNA (exon 3a-4) \\
& & & & $r_{\mathrm{s}}=0.62^{* * *}$ & PON3 protein
\end{tabular}

${ }^{*} p<0.05,{ }^{* *} p<0.01,{ }^{* *} p<0.001$.

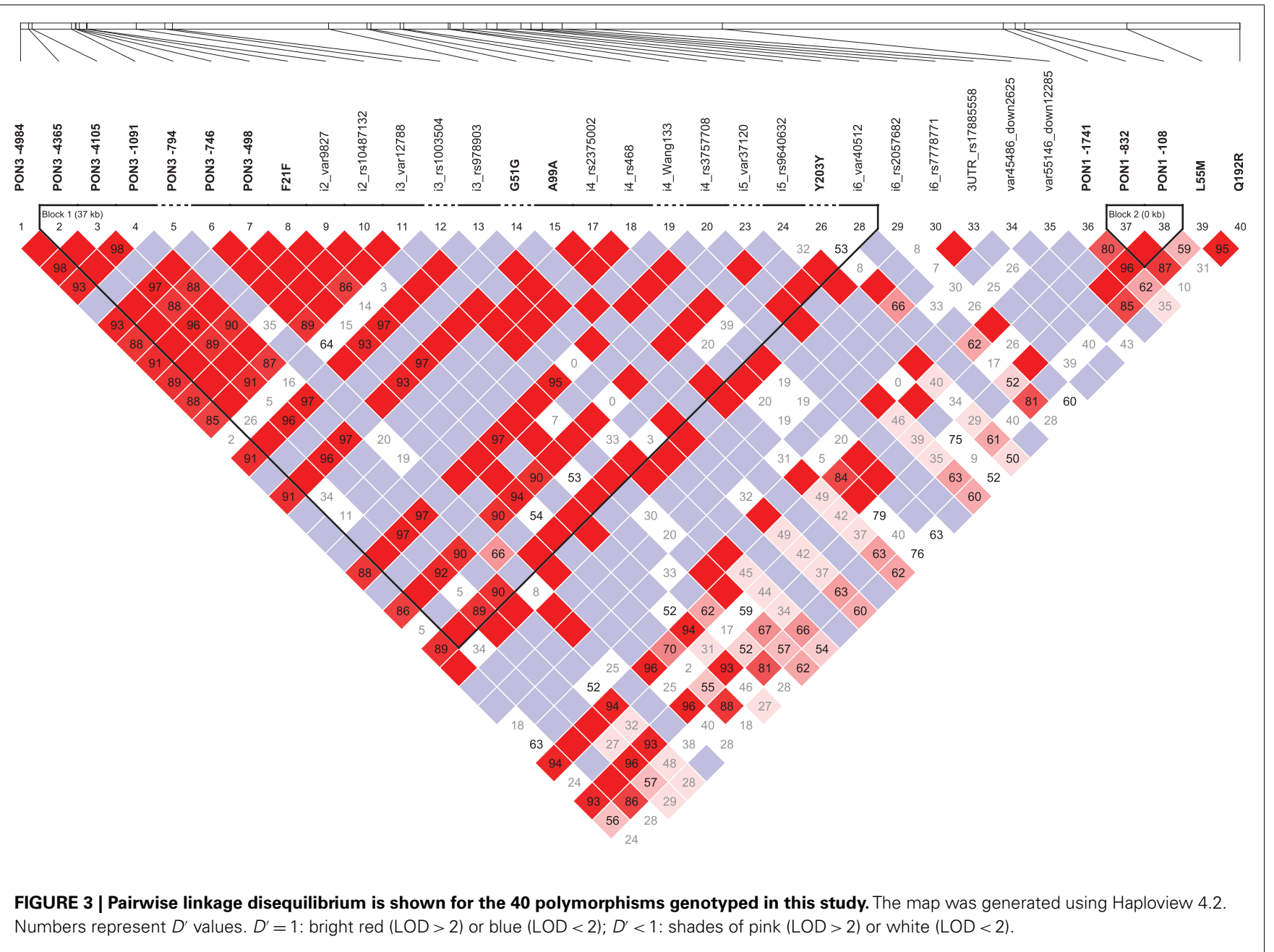




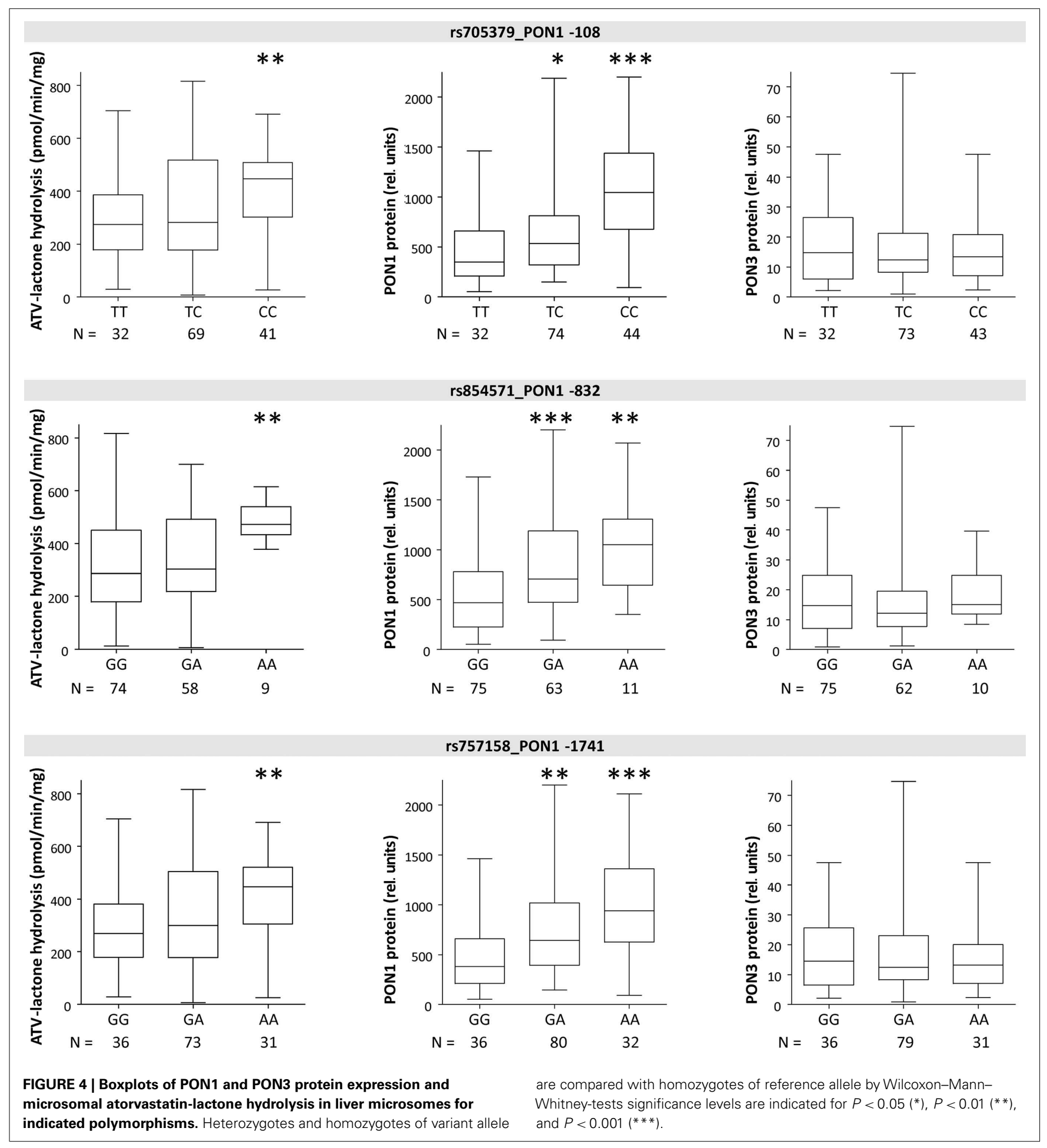

The three linked PON1 promoter polymorphisms $-108 \mathrm{~T}>\mathrm{C}$, $-832 \mathrm{G}>\mathrm{A}$, and $-1741 \mathrm{G}>\mathrm{A}$ were associated with significantly increased atorvastatin-lactone hydrolysis (up to 1.1-fold increased median values in heterozygous or 1.6- to 1.7-fold in homozygous carriers, respectively). These changes corresponded to increased PON1 protein (1.5- to 1.7-fold higher in heterozygous and 2.3- to 3.0-fold in homozygous samples, respectively; tested by Wilcoxon-Mann-Whitney, not adjusted for multiple testing) whereas PON3 protein was unchanged in these variants. Similar changes were seen for the corresponding mRNA transcripts (data not shown). Two amino acid changes in PON1, L55M, and Q192R, previously described to affect the kinetics of various substrates (Costa and Furlong, 2002) were not consistently associated with changes in either atorvastatin-lactone 


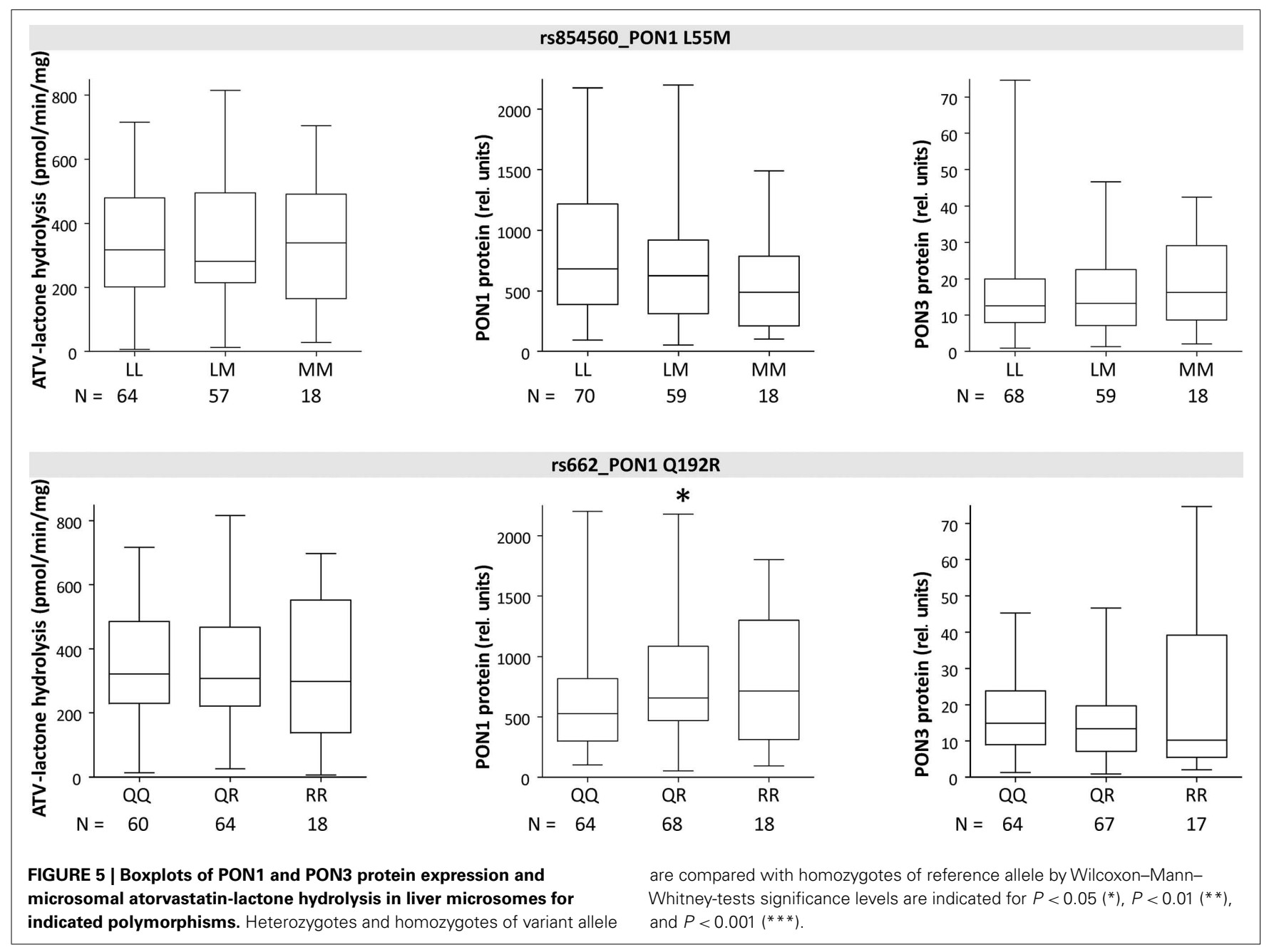

hydrolysis or PON1/PON3 protein expression, although there was a trend for decreased PON1 expression in relation to L55M and a trend for increased PON1 expression in relation to Q192R (Figure 5).

Linkage analysis of PON3 SNPs revealed F21F (rs13226149) as a suitable marker SNP for a haplotype block comprising several PON3 promoter polymorphisms, A99A (rs1053275), and several intronic variations (Figure 3). F21F was associated with increased atorvastatin-lactone hydrolysis and with increased PON1 protein expression, but not with PON3 expression (Figure 6).

In contrast to the SNPs above, which were only associated with PON1 expression, the intergenic variation at +12285 (var55146), was associated with 1.8-fold increased PON3 protein but only minimally changed activity or PON1 protein. Because only one homozygote was found for this variant, homozygous and heterozygous carriers were analyzed together (Figure 6).

\section{Analysis of PON-haplotypes and their association with PON-related phenotypes}

Based on the SNP genotyping data haplotypes for the PON-locus were deduced. To limit the number of generated haplotypes we only included SNPs with VAF $<2 \%$ (see Materials and Methods). Furthermore, because the above analysis revealed that PON3 polymorphisms are associated with changes in PON1 phenotype we defined the haplotypes such that they included both genes and the intergenic region. This lead to the definition of 13 haplotypes with predicted frequencies between 0.022 and 0.206 (Table 4). In order to classify functionally relevant haplotypes, we included the results from the univariate analyses to derive seven major haplotypes. Thus, haplotypes $* 3$ to $* 7$ comprised the PON3 linkage block including F21F and/or PON1 promoter SNPs (Figure 3). Haplotype $* 2$ was defined by the intergenic variant +12285 , and $* 1$ comprised all haplotypes lacking these variants. Of note, definition of these haplotypes did not consider the amino acid variants L55M and Q192R, which had no functional influence in this study.

Association of these seven haplotypes revealed that atorvastatin-lactone hydrolysis was markedly increased in carriers of haplotypes *2 (1.7-fold) and *6 (1.6-fold) as compared to homozygotes of haplotype $* 1$ (Figure 7 ). Less pronounced but still significant changes were also found between carriers of haplotypes $* 2, * 3, * 4$, and $* 6$ as compared to heterozygous carriers of ${ }^{*} 1$. PON1 mRNA expression was increased approximately two-fold 


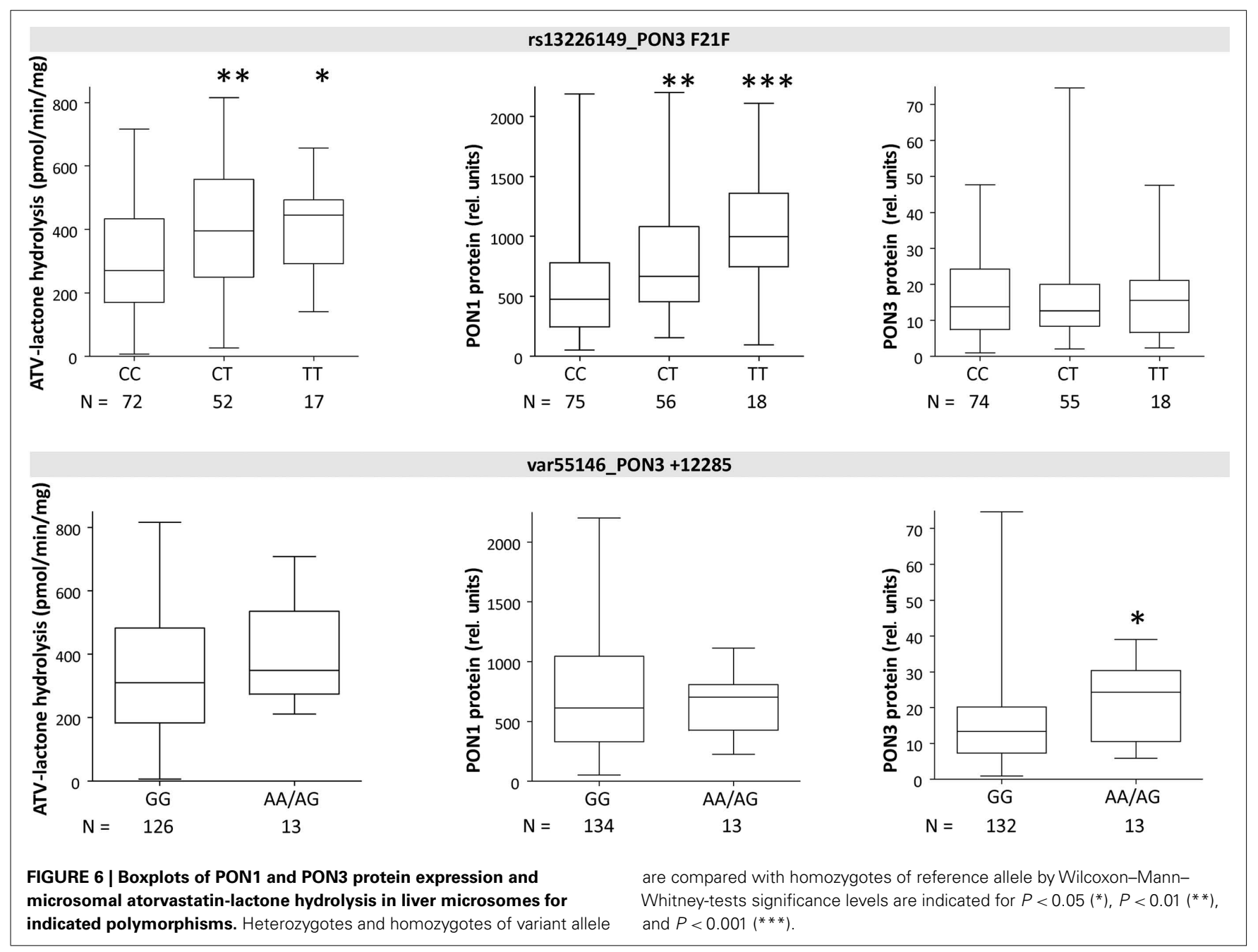

Table 4 | Structure of deduced PON-haplotypes.

\begin{tabular}{|c|c|c|c|c|c|c|c|c|c|c|c|c|c|c|c|c|c|c|c|c|c|c|c|c|c|c|c|}
\hline Haplotype ID & 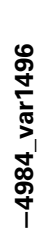 & 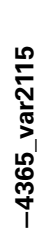 & 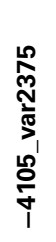 & 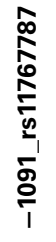 & 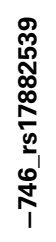 & 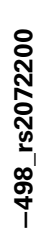 & 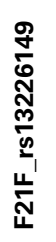 & 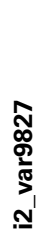 & 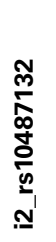 & 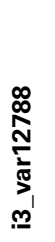 & 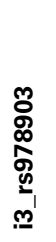 & 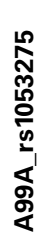 & 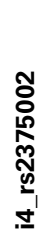 & 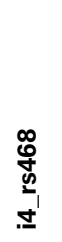 & 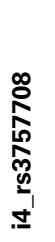 & 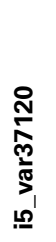 & 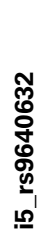 & $\begin{array}{l}\stackrel{N}{5} \\
\frac{5}{0} \\
\frac{5}{5} \\
.0\end{array}$ & 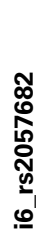 & 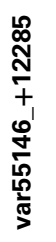 & 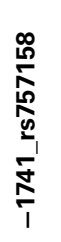 & 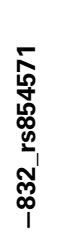 & 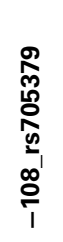 & 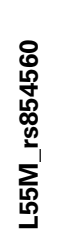 & 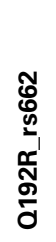 & \multicolumn{2}{|c|}{$\begin{array}{l}\text { Predicted } \\
\text { frequency }\end{array}$} \\
\hline$P O N * 1 a$ & $A$ & $A$ & $\mathrm{G}$ & $A$ & $\mathrm{C}$ & $\mathrm{C}$ & $\mathrm{C}$ & G & $\mathrm{C}$ & $\mathrm{C}$ & $\mathrm{T}$ & $\mathrm{G}$ & $A$ & $\mathrm{~T}$ & $A$ & G & $A$ & $A$ & $\mathrm{C}$ & G & $\mathrm{G}$ & $\mathrm{G}$ & $\mathrm{T}$ & A & $A$ & 0.368 & 0.206 \\
\hline$P O N * 1 C$ & & $\mathrm{~T}$ & & & & $T$ & & $A$ & $T$ & T & $\mathrm{C}$ & $A$ & & & $\mathrm{C}$ & & G & $\mathrm{G}$ & & & & & & $\mathrm{T}$ & & & 0.048 \\
\hline$P O N^{*} 1 d$ & & $\mathrm{~T}$ & & & & $\mathrm{~T}$ & & A & $\mathrm{T}$ & $\mathrm{T}$ & $\mathrm{C}$ & $A$ & & & $\mathrm{C}$ & & $\mathrm{G}$ & $\mathrm{G}$ & & & & & & $\mathrm{T}$ & $\mathrm{G}$ & & 0.031 \\
\hline$P O N * 1 e$ & & & & & & $\mathrm{~T}$ & & A & $\mathrm{T}$ & T & $\mathrm{C}$ & $A$ & & & $\mathrm{C}$ & $A$ & G & $\mathrm{G}$ & & & & & & $\mathrm{T}$ & $\mathrm{G}$ & & 0.028 \\
\hline$P O N * 2$ & & & & & & & & & & & & & & & & & & & & A & & & & & & 0.032 & 0.032 \\
\hline$P O N * 3$ & G & & $A$ & $\mathrm{G}$ & $\mathrm{T}$ & & $\mathrm{T}$ & & $T$ & $\mathrm{~T}$ & $\mathrm{C}$ & $A$ & & & $\mathrm{C}$ & & $\mathrm{G}$ & & & & $A$ & & $C$ & $\mathrm{~T}$ & $\mathrm{G}$ & 0.101 & 0.101 \\
\hline$P O N * 6$ & & & & & & & & & & & & & & & & & & & & & & A & $\mathrm{C}$ & $\mathrm{T}$ & & 0.034 & 0.034 \\
\hline$P O N * 7$ & & & & & & & & & $\mathrm{~T}$ & & & & $\mathrm{~T}$ & $A$ & & & & & G & & $A$ & & $\mathrm{C}$ & $\mathrm{T}$ & & 0.076 & 0.076 \\
\hline
\end{tabular}




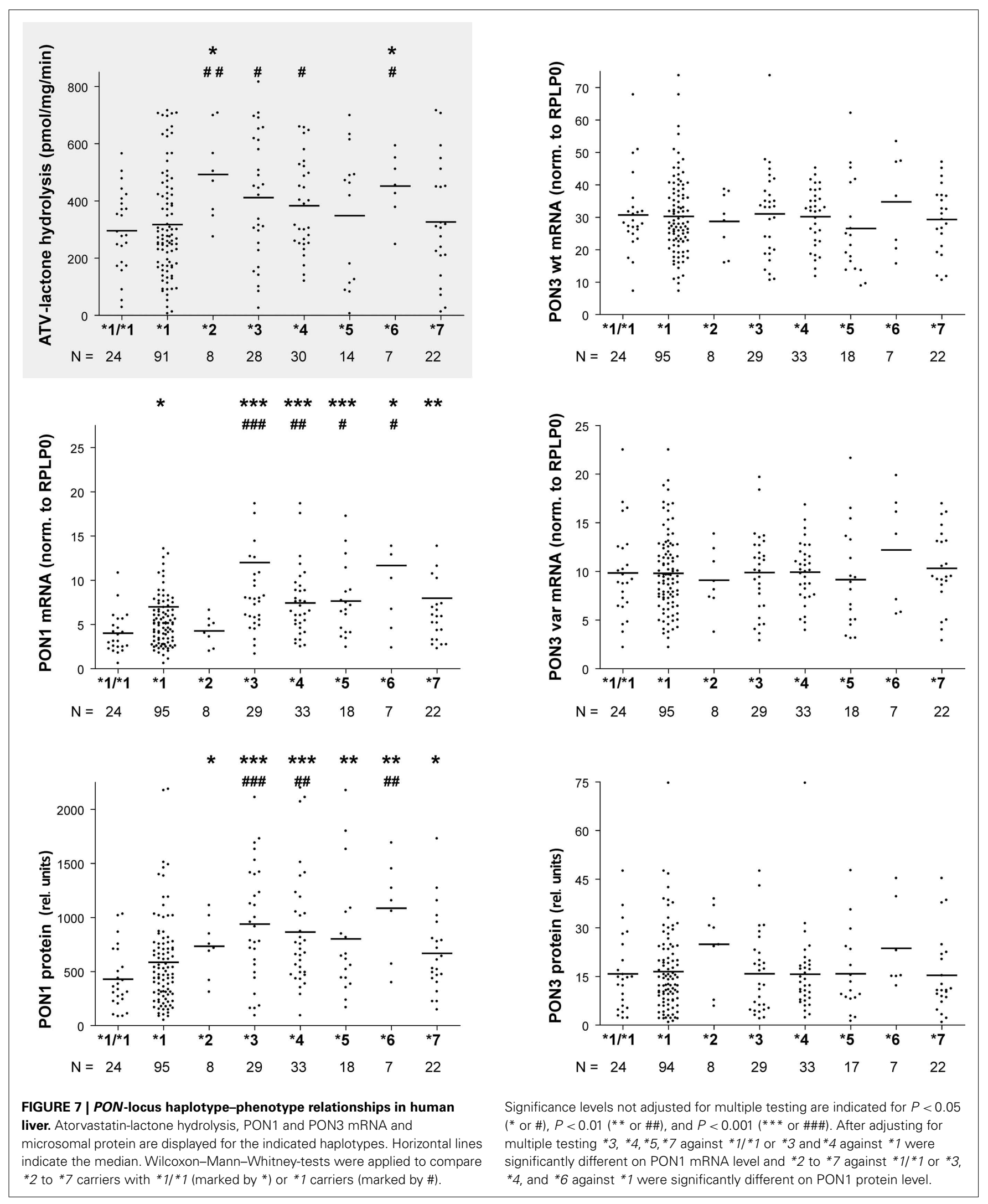


in $* 3, * 4, * 5, * 7$ and 2.7 -fold in the $* 6$ haplotype carriers but only marginally in the ${ }^{*} 2$ haplotype. PON1 protein expression resembled the mRNA pattern with $\sim 2.1$ - and 1.6-fold increased expression in $* 2$ and $* 7$, respectively, $\sim 2$-fold increase in $* 3, * 4,5$, and 3.3-fold increase in $* 6$. For PON3 no significant associations were found with respect to these haplotypes, although we noted increased expression of PON3 protein in most carriers of the *2 haplotype, which includes the above mentioned var55146.

\section{INFLUENCE OF NON-GENETIC FACTORS AND MULTIVARIATE ANALYSIS}

Univariate analysis revealed that in patients with hepatocellular carcinoma (HCC) compared to patients with metastases PON1 protein expression was decreased 1.3 -fold $(P<0.05)$, whereas in patients with cholangiocellular carcinoma (CCC) compared to patients with metastases, PON3 expression was 1.7-fold decreased $(P<0.05)$. Interestingly, clinically elevated $\mathrm{C}$-reactive protein (CRP) levels $(>8.2 \mathrm{mg} / \mathrm{l})$ were associated with 2.3 -fold lower PON1 $(P<0.01)$, 2.6-fold lower PON3 $(P<0.01)$, and 1.7-fold lower atorvastatin-lactone hydrolysis $(P<0.05)$. Similarly, elevated levels of $\gamma$-glutamyl transferase (GGT; $>64$ in men/ $>36$ in women) were associated with 1.4-fold decreased PON1 and PON3 expression as well as atorvastatin-lactone hydrolysis $(P<0.01)$. Bilirubin levels higher than $1.2 \mathrm{mg} / \mathrm{dl}$ were associated with 1.8 fold decreased PON3 expression $(P<0.01)$ and 1.3-fold decreased atorvastatin-lactone hydrolysis $(P<0.05)$. Significant differences between non-cholestasic and cholestatic patients (Nies et al., 2009) were identified for PON3 expression (decreased 1.6fold, $P<0.01$ ) and atorvastatin-lactone hydrolysis (decreased 1.4-fold, $P<0.05$ ). Presurgical drug exposure to omeprazole or pantoprazole was associated with a significant decrease of PON3 mRNA (1.3-fold, $P<0.05)$, protein (1.6-fold, $P<0.01$ ), and activity $(1.7$-fold, $P<0.01)$ compared to patients receiving no drugs.

Multivariate linear models and step-wise model selection were applied to determine the contribution of polymorphisms and non-genetic factors to atorvastatin-lactone hydrolysis and PON1 and PON3 expression variability. Figure $\mathbf{8}$ shows the fraction of observed population variability explained by polymorphisms, non-genetic factors, or both. Of the atorvastatin-lactone hydrolysis variability, $15.0 \%$ were explained by F21F (rs13226149), PON3$1091 A>G$ promoter polymorphism and the non-genetic factors sex, CRP, $\gamma$-glutamyl transferase, and cancer classification. PON1 $-108 \mathrm{~T}>\mathrm{C}$ promoter polymorphism together with non-genetic factors (noted in brackets) determined $13.1 \%$ of PON1 mRNA (smoking status, cholestasis) and $35.3 \%$ of protein expression (sex, smoking status, CRP, $\gamma$-glutamyl transferase). PON3 expression appeared to be affected mainly by non-genetic factors, which explained about $20 \%$ of protein variance when smoking status, cancer classification, CRP, bilirubin level, $\gamma$-glutamyl transferase were considered, whereas mRNA variation could not be explained reasonably.

\section{DISCUSSION}

In this study we aimed to identify the primary enzyme(s) responsible for atorvastatin-lactone hydrolysis in human liver microsomes and to characterize genetic and non-genetic factors of influence. Our results strongly suggest that both PON1 and PON3

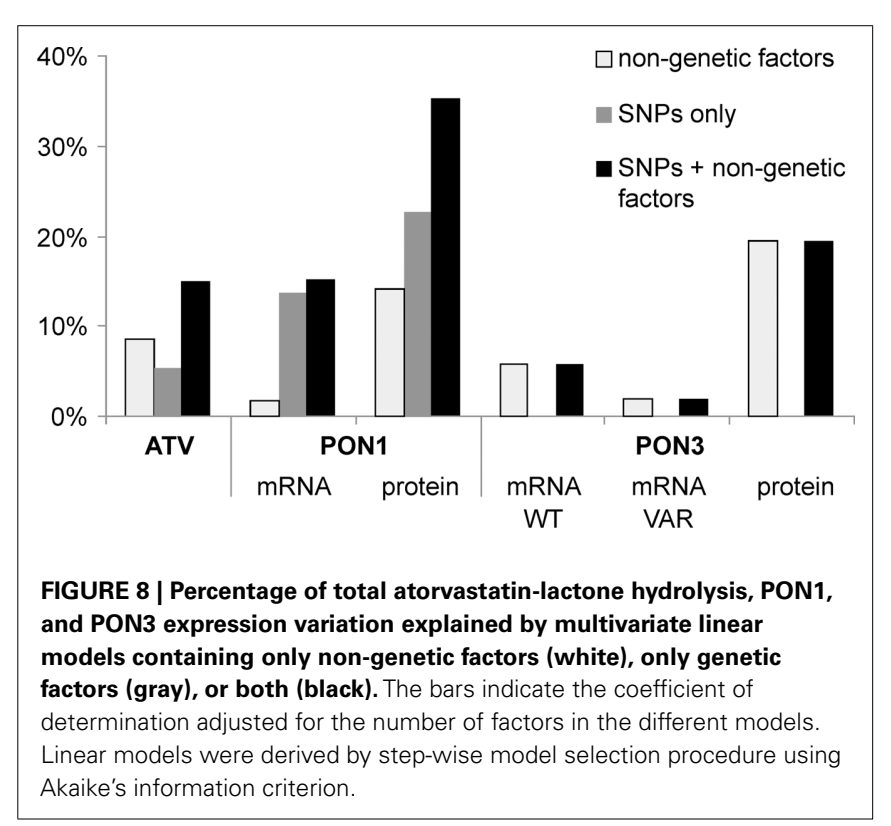

contribute to this reaction and to its interindividual variability, which is an important pathway for atorvastatin biotransformation (Figure 9). This conclusion is based on atorvastatin-lactone hydrolysis measurements and population-genetics investigations in a large human liver bank.

\section{IDENTIFICATION AND CHARACTERIZATION OF PON1 AND PON3 IN HUMAN LIVER}

We first screened expression profiles of 17 candidate esterase genes for correlation with atorvastatin-lactone hydrolysis activity, revealing several positively and negatively correlated genes. While PON1 and PON3 showed the strongest correlations, butyrylcholinesterase (BCHE) and carboxylesterase 3 (CES3) were less strong but also positively correlated. Although no information on relative expression of these enzymes in liver exists, BCHE is found in plasma $(3 \mathrm{mg} / \mathrm{l})$ in an amount comparable to PON3 $(1.8 \mathrm{mg} / \mathrm{l})$ and $\sim 30$-fold lower than PON1 (96 mg/l; Nicolet et al., 2003; Aragones et al., 2011), whereas nothing is known about substrate specificity toward statin-lactones. The negative correlation of PON2 with atorvastatin-lactone hydrolysis seems to point to some degree of co-regulation of the three paraoxonases, as it also correlated negatively with PON1 and PON3 expression data. Although we did not follow up on these other correlated candidate esterase genes, it may be assumed that they contribute to minor extent to the overall hydrolysis reaction in liver.

For PON1 and PON3 we validated these initial correlation results by real-time PCR mRNA quantification based on detailed transcript analyses. These lead to some additional observations on the mRNA level. In contrast to database information, which suggested the existence of up to four and nine transcript variants for PON1 and PON3, respectively, we identified by RT-PCR only a single, so far unknown splice-variant of PON3 with an open reading frame corresponding to 48 additional amino acids. This variant was estimated to be about three-fold less expressed. As it 


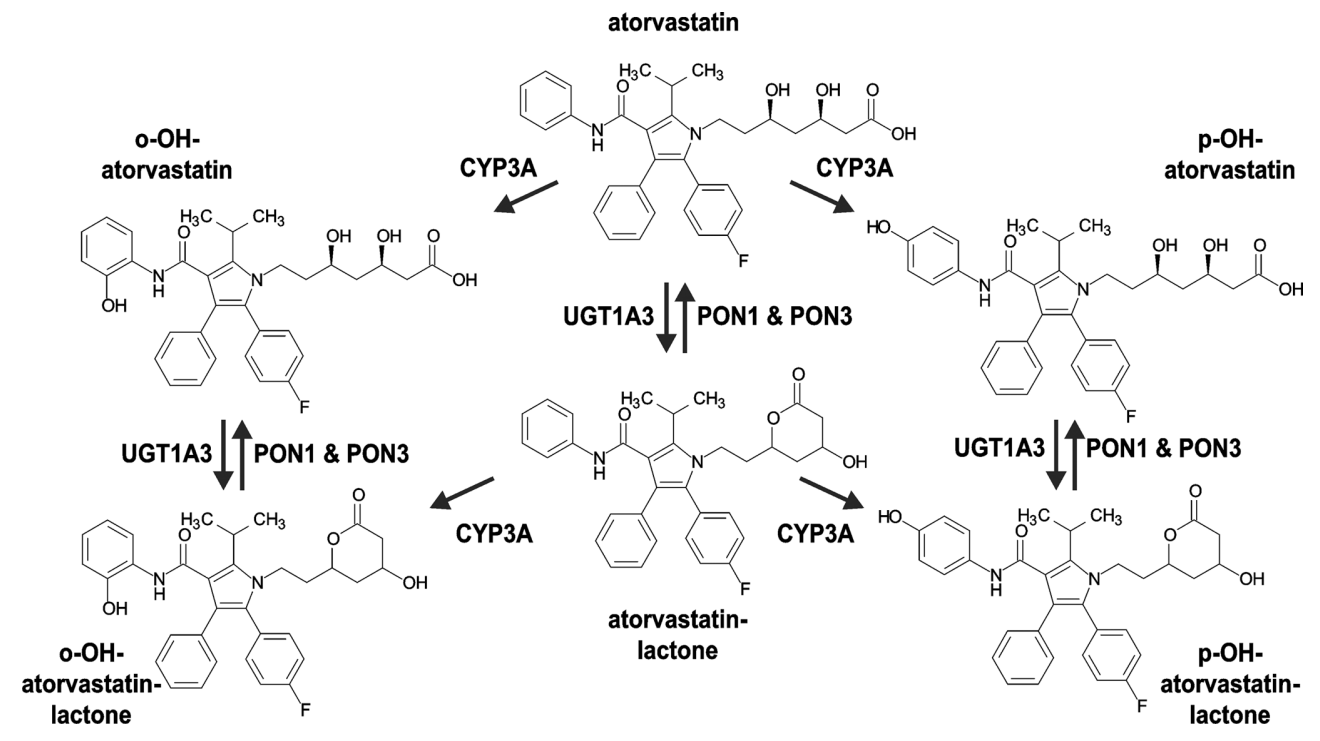

FIGURE 9 | Proposed pathway for the metabolism of atorvastatin in human liver including Hydroxylation by CYP3A enzymes, Lactonization by UGT1A3, and Hydrolysis of Lactones by PON1 and PON3.

was not detected on western blots, it is most probably either not translated or post-translationally degraded.

At the protein level our work extends previous studies showing PON1 expression in liver (Gonzalvo et al., 1998), by the observation of predominantly microsomal localization of human PON3.The similar correlation of PON1 and PON3 $\left(r_{\mathrm{s}}=0.60\right.$ and 0.62 , respectively) to atorvastatin lactonase activity was in agreement with Western blots showing comparable signal intensities for PON1 and PON3 in pooled liver microsomes, although absolute quantification could not be performed due to the lack of standards. The combined protein levels of both paraoxonases accounted for $\sim 46 \%$ of the $\sim 122$-fold variability of atorvastatin-lactone hydrolysis in the liver samples.

Furthermore, by absolute quantification of transcript levels we found PON3 normal transcript to be 4.9-fold higher expressed compared to PON1. This finding contrasts to opposite proportions reported for circulating, HDL-bound PON1 and PON3 in the bloodstream of 96 and $1.8 \mathrm{mg} / \mathrm{l}$, respectively (Aragones et al., 2011). A plausible explanation might be strongly favored secretion of PON1 due to its more pronounced glycosylation. This is supported by the fact that $\mathrm{N}$-glycans constitute sorting signals for proteins (André et al., 2009).

\section{PON GENETICS AND POLYMORPHISMS}

Although several SNPs at the PON-locus on chromosome 7 have been previously studied (Wang et al., 2003; Carlson et al., 2006) this is the first study to look at PON1 and PON3 together, which included a thorough genotyping of $P O N 3$ through analysis of 35 SNPs covering the whole gene. Evaluation of the linkage patterns of these SNPs enabled us to define 13 PON1-PON3 haplotypes, which could be grouped into seven major haplotypes based on functionally relevant SNPs. Interestingly these did not include the two amino acid variants L55M and Q192R. Crystal structure analysis revealed that Q192R affects the active histidine dyad of
PON1 (Harel et al., 2004). However the catalytic consequences are not uniform, as the kinetics of some substrates are accelerated (e.g., paraoxon) whereas others are slowed down (e.g., diazoxon) or not affected (e.g., phenylacetate; Costa and Furlong, 2002). According to our studies in liver microsomes, atorvastatin-lactone belongs to the substrates, which are not affected by either of these two variants.

In contrast to the amino acid variants PON1 promoter polymorphisms had a clear effect on expression of PON1 but not PON3. The most influential SNP for atorvastatin-lactone hydrolysis and PON1 expression appeared to be $-108 T>C$, which explained $23 \%$ of PON1 protein expression in liver, in very good agreement with a previous estimation that this SNP accounts for $\sim 22-25 \%$ of variation in PON1 serum expression in white adults (Costa and Furlong, 2002). Functional evidence for $-108 T>C$ as a causal variant includes approximately two-fold higher activity of the C-allele in a reporter gene assay (Leviev and James, 2000), presumably due to disruption of a binding site for the transcription factor Sp1 in the T-allele (Deakin et al., 2003), or a binding site for the aryl hydrocarbon receptor, AhR (Gouédard et al., 2004).

Furthermore, carriers of the high-expressor C-allele were found to show reduced LDL oxidation following treatment with atorvastatin or simvastatin, presumably due to PON1 induction via promoter binding of SREBP-2 near to the Sp1 site (Deakin et al., 2003; Sardo et al., 2005). Analysis of statin treatment of our liver donors $(N=7$, atorvastatin and simvastatin) revealed indeed a trend toward higher PON1 protein levels in treated vs. untreated $P O N 1-108 C C$ carriers $(P=0.051)$. On the other hand, protein levels of T-allele carriers on statins were similar or lower than untreated patients with the same allele. Taken together, our findings support $-108 T>C$ as a causal variant influencing PON1 expression and inducibility, as well as atorvastatin-lactone hydrolysis. 
The other two PON1 promoter polymorphisms $-832 G>A$ and $-1741 G>A$ were also associated with increased PON1 protein and atorvastatin-lactone hydrolysis. These associations may well be explained by the extensive linkage between the three promoter polymorphisms, although one study reported 1.7-fold higher activity of the $-832 \mathrm{~A}$ allele in a reporter gene assay (Leviev and James, 2000).

Although the common variations analyzed in this study did not affect PON3 expression, one variant located about $12 \mathrm{~kb}$ downstream of the last PON3 exon and about $23 \mathrm{~kb}$ upstream of PON1 (var55146, VAF $=5 \%$ ) was associated with increased protein expression of only PON3, and with marginally increased atorvastatin-lactone hydrolysis, but not with altered mRNA. Whether this association is based on the high linkage to six intronic SNPs (Figure 3) or (an) unidentified polymorphism(s) or on a downstream enhancer element of PON3 remains to be clarified. Of interest, most of the identified PON3 promoter and intronic polymorphisms, as well as F21F (rs13226149) and A99A (rs1053275), were part of a block of high linkage not affecting PON3 expression, but clearly increasing the expression of PON1.

On the other hand, as shown by multivariate analysis, nongenetic factors clearly influenced PON3 expression more than polymorphisms (Figure 8). Observed associations with CRP, $\gamma$-glutamyl transferase, bilirubin, cholestasis or treatment with omeprazole or pantoprazole leading to decreased PON3 expression have not been described before. However, decreased expression of PON1 in patients with elevated CRP and $\gamma$-glutamyl transferase and down-regulation of PON1 expression in response to inflammatory cytokines has been described before (Van Lenten et al., 2001; Han et al., 2006; Mackness et al., 2006; Araoud et al., 2010). PON1 activity has therefore been suggested as a marker for liver impairment (Marsillach et al., 2009). The associations with hepatocellular carcinoma (PON1) and cholangiocellular carcinoma (PON3) also seem to be plausible as paraoxonases have a protective effect against oxidative stress, which plays an important role in chronic liver diseases leading to liver cirrhosis and the development of carcinomas (Camps et al., 2009).

\section{MATERIALS AND METHODS CHEMICALS}

Atorvastatin calcium salt, atorvastatin- $\mathrm{d} 5$ sodium salt, atorvastatinlactone, atorvastatin- $\mathrm{d} 5$ lactone, lovastatin, lovastatin- $\mathrm{d} 3$, lovastatin hydroxy acid sodium salt, and lovastatin-d3 hydroxy acid sodium salt were purchased from Toronto Research Chemicals Inc. (North York, Canada). All other chemicals were obtained at highest available grade from Sigma-Aldrich (St. Louis, MO, USA).

\section{LIVER SAMPLES}

Liver tissue and corresponding blood samples were previously collected from patients undergoing liver surgery at the Campus Virchow, Humboldt University, Berlin, Germany. All tissue samples were examined by a pathologist and only histologically non-tumorous tissue was used. Clinical patient documentation for all samples included age, sex, medical diagnosis, presurgical medication, liver functions tests, alcohol and smoking habits, and cancer classification. Patients with hepatitis, cirrhosis or chronic alcohol use were excluded. Finally 150 liver samples, from which high quality RNA and complete documentation could be obtained, were included. The preparation of human liver microsomes had been described before (Lang et al., 2001).

\section{OUANTIFICATION OF ATORVASTATIN-ACID AND LACTONE}

Atorvastatin-lactone hydrolysis was determined in human liver microsomes. Incubation time, substrate concentration, and protein content were chosen with care to guarantee measurements within the linear range for each condition. Separate incubation experiments were always carried out together with a denaturated sample of pooled human liver microsomes to guarantee reproducibility and to subtract non-enzymatic conversion. Incubations were performed with $5 \mu \mathrm{g}$ of protein in $50 \mathrm{mM}$ Tris $\mathrm{HCl}$, $\mathrm{pH} 7.4$ and $1 \mathrm{mM} \mathrm{CaCl}_{2}$ in a total volume of $100 \mu \mathrm{l}$. The reaction was started by adding $10 \mu \mathrm{M}$ atorvastatin-lactone (dissolved in acetonitrile). Reactions were stopped after $30 \mathrm{~min}$ by adding $100 \mu \mathrm{l}$ ice-cold $250 \mathrm{mM}$ formic acid/acetonitrile and immediate cooling on ice. After adding $10 \mu \mathrm{M}$ deuterated atorvastatin and atorvastatin-lactone, the samples were centrifuged and analyzed by LC-MS-MS. HPLC separation was performed at $30^{\circ} \mathrm{C}$ on a XBridge Shield RP18 column using (A) $1 \mathrm{mM}$ formic acid and (B) acetonitrile at a flow rate of $0.4 \mathrm{ml} / \mathrm{min}$ for $20 \mathrm{~min}$. MS-MS analysis was performed on an Esquire HCT ultra ion trap mass spectrometer (Bruker Daltonics, Bremen, Germany). Lovastatin hydrolysis was determined under similar conditions using $100 \mu \mathrm{g}$ pooled HLMs and $50 \mu \mathrm{M}$ lovastatin for the performed preliminary experiment. As internal standard, deuterated lovastatin-acid and lovastatin-lactone were used. Precursor and product ions $(\mathrm{m} / \mathrm{z})$ were ATV (559 and 440.2;466.2), $\left[{ }^{2} \mathrm{H}_{5}\right]$ ATV (564 and 445.2; 471.2), ATV-L (541.2 and 448.2), $\left[{ }^{2} \mathrm{H}_{5}\right]$ ATV-L (546.2 and 453.2), LOV-A (422 and 445.1), [ $\left[{ }^{2} \mathrm{H}_{3}\right]$ LOV-A (425 and 448.1), LOV-L (404 and 427.1), $\left[{ }^{2} \mathrm{H}_{3}\right]$ LOV-L (407 and 430.1). Sodium adducts were used in the quantification of lovastatin and its metabolites. Possible quantification ranged from 0.5 to 500 pmol per sample. Gradient program and MS-MS conditions are available on request.

\section{IMMUNOBLOTTING}

Relative protein quantification of microsomal and cytosolic samples was performed by western blot analysis using monoclonal antibodies against PON1 (sc-59646, Santa Cruz; 1:1000) and PON3 (ab71994, Abcam; 1:2000). Electrophoretic separation of samples in Laemmli-buffer was done on a $10 \%$ SDSpolyacrylamide gel. Proteins were transferred by semidry-blotting onto a nitrocellulose membrane. Membranes were blocked for $1 \mathrm{~h}$ at room temperature. Primary antibodies were diluted in $1 \%$ skim milk-TBST and blots were incubated for $1 \mathrm{~h}$ at room temperature or over night at $8^{\circ} \mathrm{C}$ in this solution. Membranes were washed and incubated (under protection from light) for $30 \mathrm{~min}$ at room temperature with the corresponding secondary antibody (1:10000). Finally, membranes were washed again and the ODYSSEY infrared imaging system (LI-COR) was used for detection. Relative quantification was performed based on standard curves of pooled human liver microsomes recorded on each blot. Results were expressed in relation to pooled human liver microsomes. For molecular weight estimation, high range rainbow 
marker (14.3-220 kDa; Amersham Biosciences) was used. Lysate of primary human hepatocytes was analyzed for PON3 expression applying similar conditions. Immunoblotting of lysate was performed using a LI-COR MPX (Multiplex) Blotter.

Deglycosylation of microsomal samples was performed according to the manufacturer's protocol by incubation with endoglycosidase PNGase F (New England Biolabs, Ipswich, MA, USA) for $1 \mathrm{~h}$ at $37^{\circ} \mathrm{C}$ after denaturation at $100^{\circ} \mathrm{C}$ for $10 \mathrm{~min}$. For quantification of microsomal expression, the combined intensity of stained bands in untreated (glycosylated) samples was used.

\section{QUANTIFICATION OF mRNA EXPRESSION}

Total RNA was prepared from liver tissue by Trizol (Invitrogen, Paisley, FL, USA) extraction and using the RNeasy Mini Kit with on-column DNase treatment (Qiagen, Hilden, Germany) as described previously (Gomes et al., 2009). Only high quality RNA preparations according to Agilent Bioanalyzer (Nano-Lab Chip Kit, Agilent Technologies, Waldbronn, Germany) RIN assignment $(>7)$ were used in this study. Two hundred nanograms of total RNA was amplified and labeled using the Illumina TotalPrep RNA Amplification kit (Ambion Applied Biosystems, Darmstadt, Germany). cRNA quality was assessed by capillary electrophoresis on Agilent 2100 Bioanalyzer (Agilent Technologies). Expression levels of mRNA transcripts were assessed by the Human- 6 v3 Expression BeadChips (Illumina, Eindhoven, Netherlands). Hybridization was carried out according to the manufacturer's instructions. Quantil normalized expression data of the 15 candidate esterases was used in the analysis.

For PCR based quantification, synthesis of cDNA was performed with $1 \mu \mathrm{g}$ RNA using the TaqMan Reverse Transcription Kit (Applied Biosystems, Darmstadt, Germany) according to the supplier's instructions. Quantification of PON1, PON3 wildtype, and PON3 splice-variant mRNA was performed by specific TaqMan real-time reverse-transcription PCR on a 7900HT Fast RealTime PCR System (Applied Biosystems, Foster City, CA, USA) using exon-exon boundary spanning primers (Table A2 in Appendix; $400 \mathrm{nM}$ each) and FAM-labeled MGB probes (Table A2 in Appendix; $200 \mathrm{nM}$ ). Specificity for PON1 was confirmed using DNA plasmids constructed from PON1 and PON3 wildtype complete cDNA (see Table A3 in Appendix for full-length amplification primers), which were used as a linearized PON1 Taqman standard $(10 \mathrm{fg} / \mu \mathrm{l}-1 \mathrm{pg} / \mu \mathrm{l})$ and PON3 wildtype negative control $(1-100 \mathrm{pg} / \mu \mathrm{l})$. Position of primers and probes were shown according to cDNA NM_000446.5 (PON1) and NM_000940.2 (PON3). Specificity for PON3 wildtype and splice-variant were confirmed using DNA plasmids constructed from PON3 wildtype and splice-variant complete cDNA, which were used as linearized Taqman standard $(10 \mathrm{fg} / \mu \mathrm{l}-1 \mathrm{pg} / \mu \mathrm{l})$ and as negative control vice versa $(1-100 \mathrm{pg} / \mu \mathrm{l})$. PCR was performed using $2 \times$ universal PCR Master Mix (Applied Biosystems) in a final volume of $12.5 \mu \mathrm{l}$ and the following cycling conditions: $50^{\circ} \mathrm{C}$ for $2 \mathrm{~min} ; 95^{\circ} \mathrm{C}$ for $10 \mathrm{~min}$ followed by 40 cycles of $95^{\circ} \mathrm{C}$ for $15 \mathrm{~s}$ and $60^{\circ} \mathrm{C}$ for $1 \mathrm{~min}$. Results were normalized to RPLP0 (60S large ribosomal protein $\mathrm{P} 0$ ) and expressed in relation to the lowest value, which was set at 1.0. Four extreme values of PON1 mRNA (between rel. units 26 and 120) were excluded from subsequent analyses.

\section{GENOTYPING}

\section{Selection of polymorphisms for genotyping}

Polymorphisms for $\mathrm{PON}$-locus genotyping were derived from dbSNP database (six coding, three promoter, four intronic, one $3^{\prime}$ UTR polymorphisms) and seattle SNP database (from this database six tagging polymorphisms with a VAF $>0.05$ covered 72 polymorphisms; one tagging polymorphism with VAF $>0.02$ covered 77 polymorphisms). Additional polymorphisms were found in literature (two promoter SNPs from Marsillach et al., 2009; 12 intronic polymorphisms from Wang et al., 2003; Campo et al., 2004; Ranade et al., 2005; Carlson et al., 2006; Erlich et al., 2006; Saeed et al., 2006; Sanghera et al., 2008). Two PON1 coding polymorphisms (L55M, Q192R) were derived from Dahabreh et al. (2010). Genomic positions of polymorphisms refer to reference sequence PON3 NG_008726.1 (modified by adding PON1 NG_008779 and the intergenic region in between). SNP numbering differences occurred in various studies for PON1 promoter SNPs $(-107=-108 ;-824=-832$ according to Draganov and La $\mathrm{Du}, 2004)$. Database VAFs were extracted from Caucasian samples from one of these selections: dbSNP, build 132: (HapMap-CEU, pilot.1.CEU, PGA-EUROPEAN-PANEL); Seattle SNP (23 CEPH samples). Literature data was derived from these populations: 1143 southern Italians (Campo et al., 2004); 2634 Caucasians (Ranade et al., 2005); 949 Chinese (Wang et al., 2003). Polymorphisms were assigned by dbSNP rs number, Seattle SNP var number, amino acid change or naming within literature.

\section{MALDI-TOF MS assay}

Thirty-seven polymorphisms were genotyped by two MALDITOF MS assays. Primers (Table A4 in Appendix) were designed to specifically amplify regions around polymorphisms and carried a tag sequence (ACGTTGGATG) to avoid interactions with the MALDI-TOF MS analysis. Correct amplification was confirmed by sequencing. MassArray Assay Design (v3.0.0) was used for the design of MALDI-TOF MS extension primers. Two different assays were developed to include all 37 DNA variations analyzed (Table A5 in Appendix). Each assay consisted of preamplification by PCR, shrimp alkaline phosphatase (SAP) treatment, iPLEX primer extension, and a clean resin step. Samples were transferred to a 384 SpectroCHIP ${ }^{\circledR}$ Array (Sequenom) and analyzed in a MassArrayTM Compact mass spectrometer (Sequenom). Automated spectra acquisition was performed using Spectroacquire and data analysis was performed with MassArray Typer software v3.4. Further details are available on request.

Data for rs757158 (SNP 37) and rs854571 (SNP 38) were obtained from HumanHap300v1.1 chip analysis (Microarray Facility Tübingen Services, Tübingen, Germany). rs705379 (SNP 36) was genotyped using a predesigned TaqMan allelic discrimination assay (C_11708905_10; Applied Biosystems, Darmstadt, Germany) using TaqMan 7900HT (Applied Biosystems, Darmstadt, Germany).

\section{Statistical analysis and computational genetic analysis}

GraphPad Prism v4.00 (GraphPad Software Inc., San Diego, CA, USA) was applied for Spearman correlation analysis of (a) enzymatic atorvastatin-lactone hydrolysis activity with mRNA expression of selected candidate genes and (b) PON1 
and PON3 mRNA and protein expression. Effects of nongenetic factors on enzymatic atorvastatin-lactone hydrolysis activity and PON1/3 mRNA/protein expression were tested by Wilcoxon-Mann-Whitney-tests. Fold-changes are representing observed differences between median values of corresponding phenotypes.

Observed and expected allele and genotype frequencies within populations were tested for deviation from Hardy-Weinberg equilibrium using the online DeFinetti program (Hardy-Weinberg Equilibrium, 2011). No deviation from Hardy-Weinberg equilibrium was detected for any of the SNPs analyzed. Linkage disequilibrium (LD) plots were created by Haploview 4.2 (Barrett et al., 2005). Haplotypes for the PON-locus were generated with statistical software R v2.11.1 (The R Project for Statistical Computing, 2011) using the library haplo.stats v1.4.4. Exclusion criterion for polymorphisms was a VAF $<2 \%$. In case of $100 \%$ linked polymorphisms, only one representative was chosen and, if missing data occurred, completed by the $100 \%$ correlated polymorphisms. An iterative two-step expectation-maximization algorithm was applied to predict haplotype assignment of individuals based on activity data and polymorphisms (log-additive genetic model). Rare haplotypes were defined by a haplotype frequency $<2 \%$ and were not included in further analyses. Resulting 13 haplotypes were manually combined to seven major types according to occurrence of PON1 promoter and PON3 F21F and four promoter polymorphism (Table 4). Wilcoxon-Mann-Whitney-tests were used to compare (a) carriers of identified haplotypes vs. carriers of reference haplotypes $\left({ }^{*} 1\right.$ or $\left.{ }^{*} 1 /^{*} 1\right)$ and (b) for each of the selected $P O N 1 / 3$ polymorphisms, heterozygote and homozygote carriers of variant allele vs. homozygote carriers of reference allele.

Moreover, multivariate linear models and step-wise model selection based on Akaike's information criterion were applied to determine the contribution of polymorphisms and non-genetic factors to atorvastatin-lactone hydrolysis and PON1 and PON3 expression variability. In this analysis, atorvastatin-lactone hydrolysis and PON1 and PON3 expression were first log-transformed in order to satisfy Gaussian distribution assumption. Normality of log-transformed values was verified by normal quantile-quantile plots. Moreover, for each polymorphism, the genetic model (dominant, recessive, or log-additive) with the most significant effect on the corresponding phenotype in the univariate analyses was chosen. Relevant polymorphisms in this analysis were: PON3

\section{REFERENCES}

André, S., Kozár, T., Kojima, S., Unverzagt, C., and Gabius, H.-J. (2009). From structural to functional glycomics: core substitutions as molecular switches for shape and lectin affinity of N-glycans. Biol. Chem. 390, 557-565.

Aragones, G., Guardiola, M., Barreda, M., Marsillach, J., Beltran-Debon, R., Rull, A., Mackness, B., Mackness, M., Joven, J., Simo, J. M., and Camps, J. (2011). Measurement of serum paraoxonase- 3 concentration: method evaluation, reference values and influence of genotypes in a population-based study. J. Lipid Res. 52, 1055-1061.

Araoud, M., Neffeti, F., Douki, W., Najjar, M. F., and Kenani, A. (2010). Paraoxonase 1 correlates with butyrylcholinesterase and gamma glutamyl transferase in workers chronically exposed to pesticides. J. Occup. Health 52, 383-388.

Baer, A. N., and Wortmann, R. L. (2007). Myotoxicity associated with lipid-lowering drugs. Curr. Opin. Rheumatol. 19, 67-73.

Banerjee, I. (2010). Relationship between paraoxonase 1

- 4984 (var1496), - 1091 (rs11767787), F21F (rs13226149), PON1 -1741 (rs757158), and - 108 (rs705379). The coefficients of determination adjusted for the number of factors in the considered models were then used to specify the fraction of phenotype variability explained by (a) only polymorphisms, (b) only non-genetic factors, and (c) both, polymorphisms and non-genetic factors.

All tests were two-sided and statistical significance was defined as $P<0.05$.

\section{CONCLUSION}

PON1 and PON3 were identified as the major enzymes for hydrolysis of atorvastatin-lactone in human liver. Although this study focused on the transformation from atorvastatin-lactone to atorvastatin-acid, it is very likely that these two enzymes also convert the corresponding hydroxyl-metabolites. Based on thorough polymorphism analysis, the two common amino acid variants L55M and Q192R did not seem to be of functional importance, while several rare protein variants were not present in our collection. Our data show that PON1 expression is governed mainly by the linked promoter polymorphisms $-108 \mathrm{~T}>\mathrm{C}$, $-832 G>A$, and $-1741 G>A$, the former of which likely represents the causal variant. Accordingly, haplotypes defined on the basis of this variant show significant changes in expression and atorvastatin-lactone hydrolysis. Our extensive analysis of PON3 polymorphisms failed to identify functional polymorphisms affecting PON3, which appears to be more subject to control by non-genetic factors. As atorvastatin-lactone has been associated with toxicity, these data may help to improve concepts for safer use of statins.

\section{ACKNOWLEDGMENTS}

We thank Elke Schäffeler for helpful advice in MALDI-TOF MS genotyping assay development and Jessica K. Rieger for immunodetection of PON3 in primary human hepatocyte lysate. Britta Klumpp and Igor Liebermann are gratefully acknowledged for excellent technical assistance. The study was supported by the German Federal Ministry of Education and Science (BMBF grants 0313080I and 0315755 of the network program HepatoSys/Virtual Liver and grant 03 IS 2061C of the GANI_MED program), the 7FP EU Initial Training network program "FightingDrugFailure" (GA2009-238132), and by the Robert-Bosch Foundation, Stuttgart, Germany.

(PON1) gene polymorphisms and susceptibility of stroke: a meta-analysis. Eur. J. Epidemiol. 25, 449-458.

Barrett, J. C., Fry, B., Maller, J., and Daly, M. J. (2005). Haploview: analysis and visualization of $\mathrm{LD}$ and haplotype maps. Bioinformatics 21, 263-265.

Billecke, S., Draganov, D., Counsell, R., Stetson, P., Watson, C., Hsu, C., and La Du, B. N. (2000). Human serum paraoxonase (PON1) isozymes Q and R hydrolyze lactones and cyclic carbonate esters. Drug Metab. Dispos. 28, 1335-1342.
Bouman, H. J., Schömig, E., van Werkum, J. W., Velder, J., Hackeng, C. M., Hirschhäuser, C., Waldmann, C. Schmalz, H.-G., Ten Berg, J. M., and Taubert, D. (2011). Paraoxonase1 is a major determinant of clopidogrel efficacy. Nat. Med. 17, 110-116.

Campo, S., Sardo, A. M., Campo, G. M., Avenoso, A., Castaldo, M., D’Ascola, A., Giunta, E., Calatroni, A., and Saitta, A. (2004). Identification of paraoxonase 3 gene (PON3) missense mutations in a population of southern Italy. Mutat. Res. 546, 75-80. 
Camps, J., Marsillach, J., and Joven, J. (2009). Measurement of serum paraoxonase- 1 activity in the evaluation of liver function. World $J$. Gastroenterol. 15, 1929-1933.

Carlson, C. S., Heagerty, P. J., Hatsukami, T. S., Richter, R. J., Ranchalis, J., Lewis, J., Bacus, T. J., McKinstry, L. A., Schellenberg, G. D., Rieder, M., Nickerson, D., Furlong, C. E., Chait, A., and Jarvik, G. P. (2006). TagSNP analyses of the PON gene cluster: effects on PON1 activity, LDL oxidative susceptibility, and vascular disease. J. Lipid Res. 47, 1014-1024.

Costa, L. G., and Furlong, C. E. (2002). Paraoxonase (PON1) in Health and Disease: Basic and Clinical Aspects. Norwell, MA: Springer.

Dahabreh, I. J., Kitsios, G. D., Kent, D. M., and Trikalinos, T. A. (2010). Paraoxonase 1 polymorphisms and ischemic stroke risk: a systematic review and meta-analysis. Genet. Med. 12, 606-615.

Deakin, S., Leviev, I., Brulhart-Meynet, M.-C., and James, R. W. (2003). Paraoxonase-1 promoter haplotypes and serum paraoxonase: a predominant role for polymorphic position107, implicating the Sp1 transcription factor. Biochem. J. 372, 643-649.

Draganov, D. I. (2010). Lactonases with organophosphatase activity: structural and evolutionary perspectives. Chem. Biol. Interact. 187, 370-372.

Draganov, D. I., and La Du, B. N. (2004). Pharmacogenetics of paraoxonases: a brief review. Naunyn Schmiedebergs Arch. Pharmacol. 369, 78-88.

Draganov, D. I., Teiber, J. F., Speelman, A., Osawa, Y., Sunahara, R., and $\mathrm{La} \mathrm{Du}, \mathrm{B}$. N. (2005). Human paraoxonases (PON1, PON2, and PON3) are lactonases with overlapping and distinct substrate specificities. J. Lipid Res. 46, 1239-1247.

Erlich, P. M., Lunetta, K. L., Cupples, L. A., Huyck, M., Green, R. C., Baldwin, C. T., and Farrer, L. A. (2006). Polymorphisms in the PON gene cluster are associated with Alzheimer disease. Hum. Mol. Genet. 15, 77-85.

Furlong, C. E., Richter, R. J., Chapline, C., and Crabb, J. W. (1991). Purification of rabbit and human serum paraoxonase. Biochemistry 30, 10133-10140.

Gan, K. N., Smolen, A., Eckerson, H. W., and La Du, B. N. (1991). Purification of human serum paraoxonase/arylesterase. Evidence for one esterase catalyzing both activities. Drug Metab. Dispos. 19, 100-106.

Gomes, A. M., Winter, S., Klein, K., Turpeinen, M., Schaeffeler, E., Schwab, M., and Zanger, U. M. (2009). Pharmacogenomics of human liver cytochrome P450 oxidoreductase: multifactorial analysis and impact on microsomal drug oxidation. Pharmacogenomics 10, 579-599.

Gonzalvo, M. C., Gil, F., Hernandez, A. F., Rodrigo, L., Villanueva, E., and Pla, A. (1998). Human liver paraoxonase (PON1): subcellular distribution and characterization. J. Biochem. Mol. Toxicol. 12, 61-69.

Goosen, T. C., Bauman, J. N., Davis, J. A., Yu, C., Hurst, S. I., Williams, J. A., and Loi, C.-M. (2007). Atorvastatin glucuronidation is minimally and nonselectively inhibited by the fibrates gemfibrozil, fenofibrate, and fenofibric acid. Drug Metab. Dispos. 35, 1315-1324.

Gouédard, C., Barouki, R., and Morel, Y. (2004). Dietary polyphenols increase paraoxonase 1 gene expression by an aryl hydrocarbon receptor-dependent mechanism. Mol. Cell. Biol. 24, 5209-5222.

Han, C. Y., Chiba, T., Campbell, J. S., Fausto, N., Chaisson, M., Orasanu, G., Plutzky, J., and Chait, A. (2006). Reciprocal and coordinate regulation of serum amyloid A versus apolipoprotein A-I and paraoxonase-1 by inflammation in murine hepatocytes. Arterioscler. Thromb. Vasc. Biol. 26, 1806-1813.

Hardy-Weinberg Equilibrium. (2011). Available at: http://ihg2.helmholtzmuenchen.de/cgi-bin/hw/hwal.pl

Harel, M., Aharoni, A., Gaidukov, L., Brumshtein, B., Khersonsky, O., Meged, R., Dvir, H., Ravelli, R. B. G., McCarthy, A., Toker, L., Silman, I., Sussman, J. L., and Tawfik, D. S. (2004). Structure and evolution of the serum paraoxonase family of detoxifying and anti-atherosclerotic enzymes. Nat. Struct. Mol. Biol. 11, 412-419.

Hermann, M., Bogsrud, M. P., Molden, E., Asberg, A., Mohebi, B. U., Ose, L., and Retterstøl, K. (2006). Exposure of atorvastatin is unchanged but lactone and acid metabolites are increased several-fold in patients with atorvastatin-induced myopathy. Clin. Pharmacol. Ther. 79, 532-539.

Jacobsen, W., Kuhn, B., Soldner, A., Kirchner, G., Sewing, K. F., Kollman, P. A., Benet, L. Z., and Christians, U. (2000). Lactonization is the critical first step in the disposition of the 3-hydroxy-3-methylglutarylCoA reductase inhibitor atorvastatin. Drug Metab. Dispos. 28, 1369-1378.

Kantola, T., Kivistö, K. T., and Neuvonen, P. J. (1998). Erythromycin and verapamil considerably increase serum simvastatin and simvastatin acid concentrations. Clin. Pharmacol. Ther. 64, 177-182.

Kearney, A. S., Crawford, L. F., Mehta, S. C., and Radebaugh, G. W. (1993). The interconversion kinetics, equilibrium, and solubilities of the lactone and hydroxyacid forms of the HMG-CoA reductase inhibitor, CI-981. Pharm. Res. 10 1461-1465.

Lang, T., Klein, K., Fischer, J., Nüssler, A. K., Neuhaus, P., Hofmann, U., Eichelbaum, M., Schwab, M. and Zanger, U. M. (2001). Extensive genetic polymorphism in the human CYP2B6 gene with impact on expression and function in human liver. Pharmacogenetics 11 399-415.

Law, M., and Rudnicka, A. R. (2006) Statin safety: a systematic review. Am. J. Cardiol. 97, 52C-60C.

Leviev, I., and James, R. W. (2000). Promoter polymorphisms of human paraoxonase PON1 gene and serum paraoxonase activities and concentrations. Arterioscler. Thromb. Vasc. Biol. 20, 516-521.

Liu, T., Qian, W.-J., Gritsenko, M. A., Camp, D. G., Monroe, M. E., Moore, R. J., and Smith, R. D. (2005). Human plasma N-glycoproteome analysis by immunoaffinity subtraction, hydrazide chemistry, and mass spectrometry. J. Proteome Res. 4 2070-2080.

Lu, H., Zhu, J., Zang, Y., Ze, Y., and Qin, J. (2006). Cloning, purification, and refolding of human paraoxonase- 3 expressed in Escherichia coli and its characterization. Protein Expr. Purif. 46, 92-99.

Mackness, B., Hine, D., McElduff, P., and Mackness, M. (2006). High Creactive protein and low paraoxonase 1 in diabetes as risk factors for coronary heart disease. Atherosclerosis 186, 396-401.

Marcoff, L., and Thompson, P. D. (2007). The role of coenzyme Q10 in statin-associated myopathy: a systematic review. J. Am. Coll. Cardiol. 49, 2231-2237.

Marsillach, J., Aragonès, G., Beltrán, R., Caballeria, J., Pedro-Botet, J., Morcillo-Suárez, C., Navarro, A. Joven, J., and Camps, J. (2009). The measurement of the lactonase activity of paraoxonase- 1 in the clinical evaluation of patients with chronic liver impairment. Clin. Biochem. 42, 91-98.

Neuvonen, P. J., Niemi, M., and Backman, J. T. (2006). Drug interactions with lipid-lowering drugs: mechanisms and clinical relevance. Clin. Pharmacol. Ther. 80 , 565-581.

Nicolet, Y., Lockridge, O., Masson, P., Fontecilla-Camps, J. C., and Nachon, F. (2003). Crystal structure of human butyrylcholinesterase and of its complexes with substrate and products. J. Biol. Chem. 278, 41141-41147.

Nies, A. T., Koepsell, H., Winter, S., Burk, O., Klein, K., Kerb, R., Zanger, U. M., Keppler, D., Schwab, M., and Schaeffeler, E. (2009). Expression of organic cation transporters OCT1 (SLC22A1) and OCT3 (SLC22A3) is affected by genetic factors and cholestasis in human liver. Hepatology $50,1227-1240$.

Prueksaritanont, T., Subramanian, R. Fang, X., Ma, B., Qiu, Y., Lin, J. H., Pearson, P. G., and Baillie, T. A. (2002). Glucuronidation of statins in animals and humans: a novel mechanism of statin lactonization. Drug Metab. Dispos. 30 505-512.

Ranade, K., Kirchgessner, T. G., Iakoubova, O. A., Devlin, J. J., DelMonte, T., Vishnupad, P., Hui, L. Tsuchihashi, Z., Sacks, F. M., Sabatine, M. S., Braunwald, E., White, T. J., Shaw, P. M., and Dracopoli, N. C. (2005). Evaluation of the paraoxonases as candidate genes for stroke: Gln192Arg polymorphism in the paraoxonase 1 gene is associated with increased risk of stroke. Stroke 36, 2346-2350.

Riedmaier, S., Klein, K., Hofmann, U., Keskitalo, J. E., Neuvonen, P. J., Schwab, M., Niemi, M., and Zanger, U. M. (2010). UDPglucuronosyltransferase (UGT) polymorphisms affect atorvastatin lactonization in vitro and in vivo. Clin. Pharmacol. Ther. 87 65-73.

Saeed, M., Siddique, N., Hung, W. Y., Usacheva, E., Liu, E., Sufit, R. L., Heller, S. L., Haines, J. L., Pericak-Vance, M., and Siddique, T. (2006). Paraoxonase cluster polymorphisms are associated with sporadic ALS. Neurology 67 771-776.

Sanghera, D. K., Manzi, S., Minster, R. L. Shaw, P., Kao, A., Bontempo, F., and Kamboh, M. I. (2008). Genetic variation in the paraoxonase- 3 (PON3) gene is associated with serum PON1 activity. Ann. Hum. Genet. 72 72-81. 
Sardo, M. A., Campo, S., Bonaiuto, M., Bonaiuto, A., Saitta, C., Trimarchi, G., Castaldo, M., Bitto, A., Cinquegrani, M., and Saitta, A. (2005). Antioxidant effect of atorvastatin is independent of PON1 gene T(-107)C, Q192R and L55M polymorphisms in hypercholesterolaemic patients. Curr. Med. Res. Opin. 21, 777-784.

Shitara, Y., and Sugiyama, Y. (2006). Pharmacokinetic and pharmacodynamic alterations of 3-hydroxy-3-methylglutaryl coenzyme A (HMG-CoA) reductase inhibitors: drug-drug interactions and interindividual differences in transporter and metabolic enzyme functions. Pharmacol. Ther. 112, 71-105.

Silva, M. A., Swanson, A. C., Gandhi, P. J., and Tataronis, G. R. (2006). Statin-related adverse events: a meta-analysis. Clin. Ther. 28, 26-35.
Skottheim, I. B., Gedde-Dahl, A., Hejazifar, S., Hoel, K., and Asberg, A. (2008). Statin induced myotoxicity: the lactone forms are more potent than the acid forms in human skeletal muscle cells in vitro. Eur. J. Pharm. Sci. 33, 317-325.

Suchocka, Z., Swatowska, J., Pachecka, J., and Suchocki, P. (2006). RP-HPLC determination of paraoxonase 3 activity in human blood serum. $J$. Pharm. Biomed. Anal. 42, 113-119.

Testa, B., and Mayer, J. M. (2003). Hydrolysis in drug and prodrug metabolism: chemistry, biochemistry, and enzymology. Zürich: Helvetica Chimica Acta.

The R Project for Statistical Computing. (2011). Available at: http://www.rproject.org/

Thompson, P. D., Clarkson, P., and Karas, R. H. (2003). Statinassociated myopathy. JAMA 289, 1681-1690.
Van Lenten, B. J., Wagner, A. C., Navab, M., and Fogelman, A. M. (2001). Oxidized phospholipids induce changes in hepatic paraoxonase and ApoJ but not monocyte chemoattractant protein-1 via interleukin-6. J. Biol. Chem. 276, 1923-1929.

Wang, X., Fan, Z., Huang, J., Su, S., Yu, Q., Zhao, J., Hui, R., Yao, Z., Shen, Y., Qiang, B., and Gu, D. (2003). Extensive association analysis between polymorphisms of PON gene cluster with coronary heart disease in Chinese Han population. Arterioscler. Thromb. Vasc. Biol. 23, 328-334.

Conflict of Interest Statement: The authors declare that the research was conducted in the absence of any commercial or financial relationships that could be construed as a potential conflict of interest.
Received: 03 May 2011; paper pending published: 02 June 2011; accepted: 07 July 2011; published online: 27 July 2011. Citation: Riedmaier S, Klein K, Winter S, Hofmann $U$, Schwab $M$ and Zanger UM (2011) Paraoxonase (PON1 and PON3) polymorphisms: impact on liver expression and atorvastatinlactone hydrolysis. Front. Pharmacol. 2:41. doi: 10.3389/fphar.2011. 00041

This article was submitted to Frontiers in Pharmacogenetics and Pharmacogenomics, a specialty of Frontiers in Pharmacology.

Copyright $(\odot 2011$ Riedmaier, Klein, Winter, Hofmann, Schwab and Zanger. This is an open-access article subject to a nonexclusive license between the authors and Frontiers Media SA, which permits use, distribution and reproduction in other forums, provided the original authors and source are credited and other Frontiers conditions are complied with. 


\section{APPENDIX}

Table A1 | Characteristics and variant allele frequencies (VAF) of polymorphisms determined in 150 Caucasian samples.

\begin{tabular}{|c|c|c|c|c|c|c|c|c|}
\hline \multirow[t]{2}{*}{ SNP } & \multirow[t]{2}{*}{ Gene } & \multirow{2}{*}{$\begin{array}{l}\text { SNP ID dbSNP or } \\
\text { Seattle SNP }\end{array}$} & \multirow{2}{*}{$\begin{array}{l}\text { Genomic } \\
\text { position }\end{array}$} & \multirow{2}{*}{$\begin{array}{l}\text { Base } \\
\text { change }\end{array}$} & \multirow{2}{*}{$\begin{array}{l}\text { Residue } \\
\text { change }\end{array}$} & \multirow[t]{2}{*}{ Region } & \multicolumn{2}{|c|}{ VAF } \\
\hline & & & & & & & $\begin{array}{l}\text { IKP } \\
\text { liver } \\
\text { bank }\end{array}$ & $\begin{array}{l}\text { Database; } \\
\text { literature }\end{array}$ \\
\hline 1 & PON3 & var1496 & 42 & $A / G$ & & Promoter & 0.295 & 0.200 \\
\hline 2 & PON3 & var2115 & 661 & $\mathrm{~A} / \mathrm{T}$ & & Promoter & 0.087 & 0.200 \\
\hline 3 & PON3 & var2375 & 921 & $\mathrm{G} / \mathrm{A}$ & & Promoter & 0.288 & 0.200 \\
\hline 4 & PON3 & rs11767787 & 3935 & $\mathrm{~A} / \mathrm{G}$ & & Promoter & 0.309 & 0.241 \\
\hline 5 & PON3 & rs17885453 & 4232 & $\mathrm{C} / \mathrm{T}$ & & Promoter & 0.014 & 0.023 \\
\hline 6 & PON3 & rs17882539 & 4280 & $\mathrm{C} / \mathrm{T}$ & & Promoter & 0.295 & 0.181 \\
\hline 7 & PON3 & rs2072200 & 4528 & $\mathrm{C} / \mathrm{G}$ & & Promoter & 0.198 & 0.272 \\
\hline 8 & PON3 & rs13226149 & 5088 & $\mathrm{C} / \mathrm{T}$ & $\mathrm{F} 21 \mathrm{~F}$ & Exonic & 0.309 & 0.250 \\
\hline 9 & PON3 & var9827 & 8372 & $\mathrm{G} / \mathrm{A}$ & & Intronic & 0.183 & 0.300 \\
\hline 10 & PON3 & rs10487132 & 10383 & $\mathrm{~T} / \mathrm{C}$ & & Intronic & 0.360 & 0.383 \\
\hline 11 & PON3 & var12788 & 11333 & $\mathrm{C} / \mathrm{T}$ & & Intronic & 0.486 & 0.430 \\
\hline 12 & PON3 & rs1003504 & 11895 & $A / G$ & & Intronic & 0.018 & 0.022 \\
\hline 13 & PON3 & rs978903 & 26521 & $\mathrm{~T} / \mathrm{C}$ & & Intronic & 0.497 & 0.458 \\
\hline 14 & PON3 & Campo219 & 29055 & $\mathrm{C} / \mathrm{G}$ & G51G & Intronic & 0.004 & 0.007 \\
\hline 15 & PON3 & rs1053275 & 29133 & $\mathrm{G} / \mathrm{A}$ & A99A & Exonic & 0.493 & 0.466 \\
\hline 16 & PON3 & rs2375003 & 29155 & $\mathrm{G} / \mathrm{A}$ & D107N & Exonic & 0 & 0 \\
\hline 17 & PON3 & rs2375002 & 29330 & $\mathrm{~T} / \mathrm{A}$ & & Intronic & 0.09 & 0.043 \\
\hline 18 & PON3 & rs468 & 32735 & $\mathrm{~T} / \mathrm{C}$ & & Intronic & 0.096 & 0.025 \\
\hline 19 & PON3 & Wang.133 & 33772 & $\mathrm{G} / \mathrm{T}$ & & Intronic & 0.004 & 0.227 \\
\hline 20 & PON3 & rs3757708 & 33775 & $\mathrm{~A} / \mathrm{C}$ & & Intronic & 0.489 & 0.483 \\
\hline 21 & PON3 & rs17879114 & 33898 & $\mathrm{G} / \mathrm{A}$ & V126V & Exonic & 0 & 0 \\
\hline 22 & PON3 & rs17878827 & 33956 & $\mathrm{G} / \mathrm{A}$ & E146K & Exonic & 0 & 0 \\
\hline 23 & PON3 & var37120 & 35664 & $\mathrm{G} / \mathrm{A}$ & & Intronic & 0.036 & 0.110 \\
\hline 24 & PON3 & rs9640632 & 36134 & $A / G$ & & Intronic & 0.482 & 0.483 \\
\hline 25 & PON3 & rs17883013 & 37354 & $\mathrm{C} / \mathrm{A}$ & A179D & Exonic & 0 & 0 \\
\hline 26 & PON3 & rs17880470 & 37427 & $\mathrm{~T} / \mathrm{C}$ & Y203Y & Exonic & 0.014 & 0.022 \\
\hline 27 & PON3 & Ranade & 38537 & $A / G$ & Y233C & Exonic & 0 & 0 \\
\hline 28 & PON3 & var40512 & 39056 & $\mathrm{~A} / \mathrm{G}$ & & Intronic & 0.183 & 0.300 \\
\hline 29 & PON3 & rs2057682 & 39924 & $\mathrm{C} / \mathrm{G}$ & & Intronic & 0.142 & 0.076 \\
\hline 30 & PON3 & rs7778771 & 40352 & $\mathrm{C} / \mathrm{T}$ & & Intronic & 0.014 & 0.025 \\
\hline 31 & PON3 & Campo931 & 41269 & $\mathrm{~T} / \mathrm{A}$ & S311T & Exonic & 0 & 0.002 \\
\hline 32 & PON3 & Campo971 & 41309 & $\mathrm{G} / \mathrm{A}$ & G324D & Exonic & 0 & 0.006 \\
\hline 33 & PON3 & rs17885558 & 41438 & $\mathrm{C} / \mathrm{T}$ & & 3(UTR & 0.014 & 0.025 \\
\hline 34 & & var45486 & (44028) & $\mathrm{G} / \mathrm{T}$ & & Intergenic & 0.014 & 0.050 \\
\hline 35 & & var55146 & (53688) & $\mathrm{G} / \mathrm{A}$ & & Intergenic & 0.050 & 0.100 \\
\hline 36 & PON1 & rs757158 & (75164) & $\mathrm{G} / \mathrm{A}$ & & Promoter & 0.486 & 0.408 \\
\hline 37 & PON1 & rs854571 & (76073) & $A / G$ & & Promoter & 0.285 & 0.267 \\
\hline 38 & PON1 & rs705379 & (76797) & $\mathrm{T} / \mathrm{C}$ & & Promoter & 0.460 & 0.389 \\
\hline 39 & PON1 & rs854560 & (84608) & $\mathrm{T} / \mathrm{A}$ & L55M & Exonic & 0.335 & 0.397 \\
\hline 40 & PON1 & rs662 & (93246) & $A / G$ & Q192R & Exonic & 0.352 & 0.358 \\
\hline
\end{tabular}


Table A2 | Amplification primers used for quantitative PCR.

\begin{tabular}{|c|c|c|c|c|}
\hline Name & cDNA position & Primer sequence $\left(5^{\prime} \rightarrow 3^{\prime}\right)$ & $\begin{array}{l}\text { Amplification } \\
\text { product (bp) }\end{array}$ & Purpose \\
\hline TQ_PON3_for & $181-209$ & TGAAGATATTGATATACTTCCTAGTGGGC & & For primer \\
\hline TQ_PON3_WT_rev & $297-316$ & TGCCCTTGGGTTTTGTTCAT & Wt: 136, var: 132 & Rev primer \\
\hline TQ_PON3_VAR_rev & 67-86 (Exon splVar) & TATTTGCCGTTCTGCAGCCT & & Rev primer \\
\hline TQ_PON3_WT & $218-234$ & 6FAM-ATCTCCAGTGGATTAAA-MGB & & Probe \\
\hline TQ_PON3_VAR & 218-8 (Exon splVar) & 6FAM-ATCTCCAGTCTGCAGGT-MGB & & Probe \\
\hline PON1_Hs00166557_m1 & 994-1018 & TCCTGCATCAGAGGTGCTTCGAATC & 122 & Mix \\
\hline
\end{tabular}

Table A3 | Amplification primers used for plasmid generation.

\begin{tabular}{lllr}
\hline Name & cDNA Position & Primer sequence $\left(\mathbf{5}^{\prime} \rightarrow \mathbf{3}^{\prime}\right)$ & $\begin{array}{c}\text { Amplification } \\
\text { product (bp) }\end{array}$ \\
\hline PON3_komplett_f & $1-16$ & AGATCTAGTCGCCGCTGGGCAC & 1203 \\
PON3_komplett_r & $1170-1193$ & AAGCTTTTGGTGTTGCTATTTACTTAC & For primer \\
PON1_kompl_neu_f & $95-115$ & ACCATGGCGAAGCTGATTGCG & Rev primer \\
PON1_kompl_neu_r & $1306-1327$ & GAATTCTACACATCATATCACTCCCAGT & For primer \\
\hline
\end{tabular}

Table A4 | Amplification primers used in MALDI-TOF MS genotyping.

\begin{tabular}{|c|c|c|c|c|}
\hline Name & Genomic position & Primer sequence $\left(5^{\prime} \rightarrow 3^{\prime}\right)$ & $\begin{array}{l}\text { Amplification } \\
\text { product (bp) }\end{array}$ & SNP ID \\
\hline PON3_1f & 3882-3982 & ACGTTGGATGTAAGCAATCTGTGCTGCAGG & 111 & rs11767787 \\
\hline PON3_2f & $4148-4256$ & ACGTTGGATGTCGGTGGAACCTAACAGAAC & 119 & rs17885453 \\
\hline PON3_2r & & ACGTTGGATGACTGAAGATGCGGGAAGA & & \\
\hline PON3_3f & $4256-4318$ & ACGTTGGATGTTCCTCССССТCСАAССТ & 73 & rs17882539 \\
\hline PON3_6f & $4496-4580$ & ACGTTGGATGAAGGCAATCGAAGCGAAGAG & 95 & rs2072200 \\
\hline PON3_6r & & ACGTTGGATGAGGTAAGGCACGAAGGTCAG & & \\
\hline PON3_7f & $4944-5039$ & ACGTTGGATGATCCGTACGCGAGGCAGGAA & 106 & rs17886586 \\
\hline PON3_7r & & ACGTTGGATGACGAGCTTCCCCATGGTCTC & & \\
\hline PON3_8f & $5058-5156$ & ACGTTGGATGGGTCGGCCTGTCCTTAGTC & 109 & rs 13226149 \\
\hline PON3_11_12r & & ACGTTGGATGCCCCTTATCCCTAAACATAC & & \\
\hline PON3_13f & 32673-32769 & ACGTTGGATGGTGAGAGTACTTTTCTTCTCC & 107 & rs468 \\
\hline PON3_13r & & ACGTTGGATGGTCATCTCCCTTAATTATG & & \\
\hline PON3_14f & $33844-33927$ & ACGTTGGATGGATAGGGGTAACTTTCTTGG & 94 & rs17879114 \\
\hline PON3_14r & & ACGTTGGATGATGTGGGGATGATTCACAAC & & \\
\hline PON3_15f & $33928-34038$ & ACGTTGGATGCCGCACAATACTTTCATTCC & 121 & rs 17878827 \\
\hline PON3_15r & & ACGTTGGATGGAAGTCCACTGTGGAGATAT & & \\
\hline PON3_16f & 36189-36095 & ACGTTGGATGTCAGGCTCCTCTTTAGATCC & 105 & rs9640632 \\
\hline PON3_16r & & ACGTTGGATGCTCTGGGAAGTACATCAGAC & & \\
\hline PON3_17f & $37280-37383$ & ACGTTGGATGGGGAGTTGGTAAAATAGTGG & 114 & rs17883013 \\
\hline PON3_17r & & ACGTTGGATGTGGGTCTCTTTTTCCACCTC & & \\
\hline
\end{tabular}


Table A4 | Continued

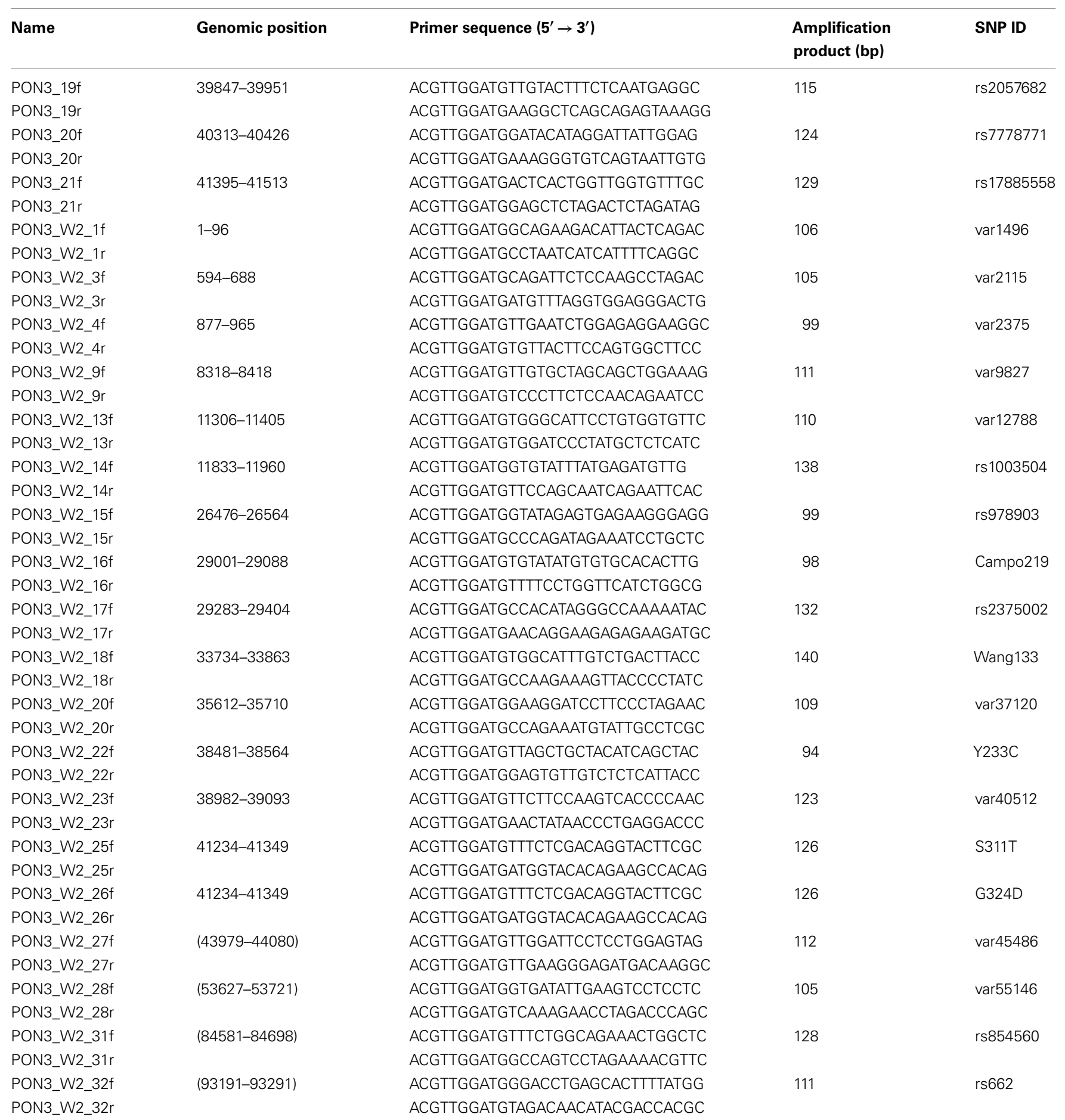


Table A5 | Extension primers used in MALDI-TOF MS genotyping.

\begin{tabular}{|c|c|c|c|c|c|c|}
\hline No. & Name & $\begin{array}{l}\text { Genomic } \\
\text { position }\end{array}$ & Assay & Primer sequence $\left(5^{\prime} \rightarrow 3^{\prime}\right)$ & $\begin{array}{l}\text { Mass of ampl. } \\
\text { prod. (Da) }\end{array}$ & SNP ID \\
\hline 1 & PON3_W2_1e & 42 & 2 & ggCCTTTCTTAAGAAAGGGCTAAT & 7391.8 & var1496 \\
\hline 3 & PON3_W2_4e & 921 & 2 & GTAGGCCAAGTTAAGAAAC & 5869.9 & var2375 \\
\hline 4 & PON3_W2_5e & 3935 & 2 & AATTATCAACACAATCTCTGGAG & 7015.6 & rs11767787 \\
\hline 5 & PON3_2e & 4232 & 1 & TGCTACTTTGCCCGAACT & 5425.5 & rs17885453 \\
\hline 7 & PON3_6e & 4528 & 1 & АTCTTCTCCAGGATTTGGGGCAC & 7030.6 & rs2072200 \\
\hline 8 & PON3_8e & 5088 & 1 & agTAGTCGGGGAGATGTT & 5634.7 & rs13226149 \\
\hline 9 & PON3_W2_9e & 8372 & 2 & ACGCCTTTCCTGAATT & 4807.1 & var9827 \\
\hline 10 & PON3_10e & 10383 & 1 & cGCCTATGCACAACTATCATTA & 6638.3 & rs10487132 \\
\hline 11 & PON3_W2_13e & 11333 & 2 & GGCTTTTTTAGTTGACTGGTTTACCC & 7949.2 & var12788 \\
\hline 16 & PON3_12e & 29155 & 1 & CCATGTGGATTAAATAATTCTTTGT & 7661 & rs2375003 \\
\hline 17 & PON3_W2_17e & 29330 & 2 & cCAAGGTTTTATACCTATTTATCATTT & 8189.4 & rs2375002 \\
\hline 18 & PON3_13e & 32735 & 1 & gТTСТССАТСТССТСАТТСС & 5929.9 & rs468 \\
\hline 19 & PON3_W2_18\#1e & 33772 & 2 & ACCTATCATGTAGACTGTGAG & 6445.2 & Wang133 \\
\hline 20 & PON3_W2_18\#2e & 33797 & 2 & TTTCTTCTTACATCTTGCATTT & 6607.3 & rs3757708 \\
\hline 21 & PON3_14e & 33898 & 1 & gTTCCATGTAGACAATACTGT & 6420.2 & rs17879114 \\
\hline 22 & PON3_15e & 33956 & 1 & AGAGAACGTTGTTGTTCCT & 5833.8 & rs17878827 \\
\hline 23 & PON3_W2_20e & 35664 & 2 & CATGGCCCTACCAATAACAC & 6014.9 & var37120 \\
\hline 24 & PON3_16e & 36134 & 1 & GTTCCAGCTGCTGCTA & 4848.2 & Campo219 \\
\hline 25 & PON3_17e & 37354 & 1 & AATAGTGGTCTCTGGTG & 5256.4 & rs2375002 \\
\hline 26 & PON3_18e & 37427 & 1 & cGATCTTCGCTGGACTTA & 5465.6 & rs17880470 \\
\hline 34 & PON3_W2_27e & 44028 & 2 & ССАTTCTTTCCAAAGGATAG & 6076 & var45486 \\
\hline 35 & PON3_W2_28e & 53688 & 2 & gACCTTGAGGCAATGTG & 5250.4 & var55146 \\
\hline 39 & PON3_W2_31e & 84608 & 2 & AACTGGCTCTGAAGAC & 4890.2 & rs854560 \\
\hline 40 & PON3_W2_32e & 93246 & 2 & gTTCTTGACCCCTACTTAC & 5689.7 & rs662 \\
\hline
\end{tabular}

